University of Rhode Island

DigitalCommons@URI

Open Access Dissertations

2017

\title{
Relationship and Power Dynamics in Women's Same Sex Abusive Couples
}

April D. Trotman

University of Rhode Island, april.trotman@gmail.com

Follow this and additional works at: https://digitalcommons.uri.edu/oa_diss

\section{Recommended Citation}

Trotman, April D., "Relationship and Power Dynamics in Women's Same Sex Abusive Couples" (2017). Open Access Dissertations. Paper 591.

https://digitalcommons.uri.edu/oa_diss/591

This Dissertation is brought to you for free and open access by DigitalCommons@URI. It has been accepted for inclusion in Open Access Dissertations by an authorized administrator of DigitalCommons@URI. For more information, please contact digitalcommons-group@uri.edu. 


\title{
RELATIONSHIP AND POWER DYNAMICS IN WOMEN'S SAME SEX ABUSIVE COUPLES
}

\author{
BY \\ APRIL TROTMAN
}

\begin{abstract}
A DISSERTATION SUBMITTED IN PARTIAL FULFILLMENT OF THE REQUIREMENTS FOR THE DEGREE OF

DOCTOR OF PHILOSOPHY

IN

PSYCHOLOGY
\end{abstract}

UNIVERSITY OF RHODE ISLAND

2017 
DOCTOR OF PHILOSOPHY DISSERTATION

$\mathrm{OF}$

APRIL TROTMAN

APPROVED:

Dissertation Committee:

Major Professor Patricia Morokoff

Kathryn Quina

Ginette Ferszt

Nasser H. Zawia

DEAN OF THE GRADUATE SCHOOL

UNIVERSITY OF RHODE ISLAND

2017 


\begin{abstract}
Intimate partner violence (IPV) is a widespread occurrence in the United States, particularly in women's same sex relationships. Unfortunately, beyond preliminary data on prevalence rates, little is known about how the power dynamics in women's same sex IPV compares to that of heterosexual couples. The purpose of the current study is to describe the types of abuse women experience in same sex relationships, illustrate the role of power and control over the course of an abusive relationship, and demonstrate the extent to which abuse changes over time within a relationship and during a woman's subsequent relationships. Using qualitative methods, twelve women described their experiences of same sex partner violence through phone interviews. All women in the sample had experienced at least one past instance of same sex IPV, though they could identify sexually however they chose. Interviews were analyzed using manifest content analysis to describe common responses to each research questions from the women's stories. Results suggest that women experienced all forms of IPV in same sex relationships, endured several domains of powerless and lack of control over their partners, and described abuse as a one-sided, increasingly intense trajectory with their first same sex partner. Participants also provided helpful reflections and suggestions for healthcare professionals and therapists based on their experiences with help seeking. Implications for provider education and therapeutic interventions are discussed.
\end{abstract}




\section{ACKNOWLEDGMENTS}

I would like to thank my major professor, Dr. Patricia Morokoff, for encouraging me to find a way to take on such an ambitious research topic and supporting my efforts to complete this project. I made a lofty goal for myself to take on this project - I appreciate you helping me see it through to the end. I'm proud to be your last doctoral mentee! I would also like to express my thanks to my committee members, Drs. Kat Quina and Ginette Ferszt for their expertise and input when helping me craft this study. Your kindness, compassion, and openness to help me will forever be appreciated. I would also like to thank my defense chair, Dr. Donna SchwartzBarcott for helping me to develop my ideas in your qualitative methods class. Your contagious curiosity and excitement about all forms of qualitative methods certainly rubbed off on me, in a good way. I'm glad you decided to join us on such an important topic.

I must acknowledge my classmates, friends, and many research assistants who pushed me, motivated me, and helped to carry the extra load involved with completing this project. I am also grateful for my friend and partner, Roxanne Neumann for her kind words, suggestions, and endless offers to assist me whenever I needed her especially at the end! Lastly, I want to thank the women who expressed any interest in my research, whether you only filled out a few survey questions, or you completed a whole phone interview. I am in awe of your strength, your courage, your insight, and your willingness to help other women benefit from your painful experiences. I hope, if nothing else, I did your stories justice. You inspire me. Thank you all, for everything. 


\section{PREFACE}

This project holds a special meaning for me, as I have imagined for many years that I would like to be able to talk to women about their experience of domestic violence. I have heard stories throughout my life from the women in my family, my friends, my students, and my patients. From each story I learn about the strength women have had to uncover to endure challenging and often dangerous situations with their intimate partners. Some women can overcome the impact of abuse and a broken spirit, others not. The differences in the way women respond has always fascinated me and even after completing this dissertation, I still have so many questions about how women make sense of intimate partner violence, especially with a same sex partner. Through these interviews and my work as a therapist, I have also been able to reflect on my own experiences with these issues. Like many of these women, it is much different to recognize what has happened to someone else compared to yourself. Nonetheless, I have dedicated my training in my clinical psychology doctoral program to understanding women's experiences, particularly the traumas and pain, so that I could effectively help them work through various life obstacles or emotional struggles. Given my career aspirations and goals, using a qualitative approach was naturally the best way to gain the insight of the brave women who participated in my study. And of course, it was just as important for me to conduct all the interviews myself - not only to gain a direct perspective from each woman, but to have the ability to guide the story to enhance my own understanding. Lastly I hoped to utilize my gentle, empathic therapeutic style to facilitate a warm, safe environment in what could have been a very cold and awkward conversation given the interviews occurred over the phone with 
someone they had never met before. It was probably more important to me to connect with each woman and develop a greater sense of knowing her than anything else. It is my sincere wish they felt that.

The lack of research in this area is truly unfortunate and in some ways this project feels like a great way to push the field into investigating same sex partner violence in a more nuanced fashion. I certainly see this issue as more complex and less clear-cut than I did before, while at the same time having an appreciation for the women who both experience and perpetuate violence against their same sex partners. I am excited to not only apply what I have learned in my clinical work with women who have experienced domestic violence and other relationship issues, but to educate others about how they can be a positive force in this area. 


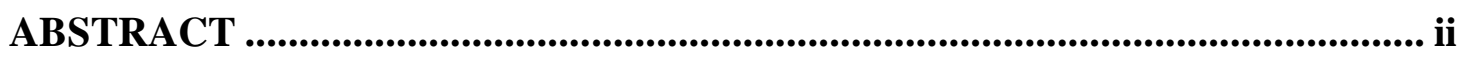

ACKNOWLEDGMENTS....................................................................................... ii

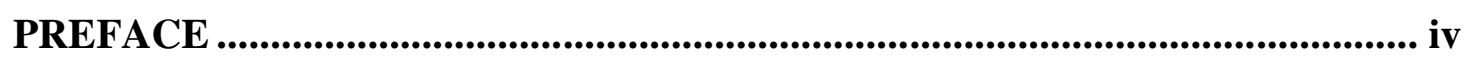

TABLE OF CONTENTS ................................................................................................... vi

LIST OF TABLES ........................................................................................................... vii

LIST OF APPENDICES................................................................................... vii

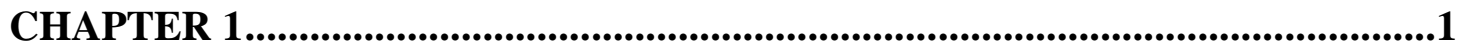

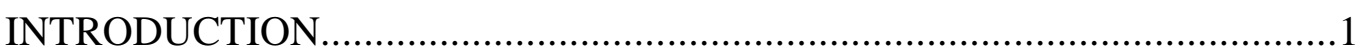

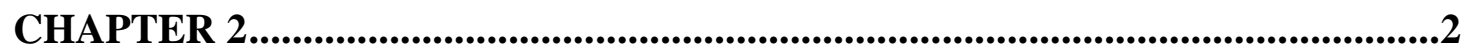

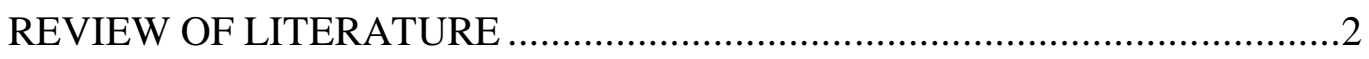

CHAPTER 3...................................................................................................................15

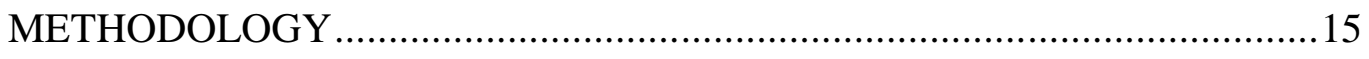

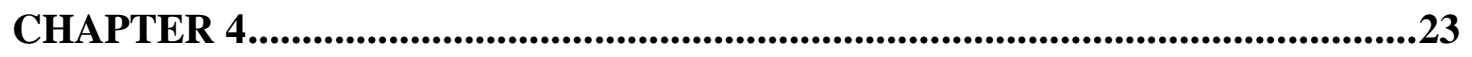

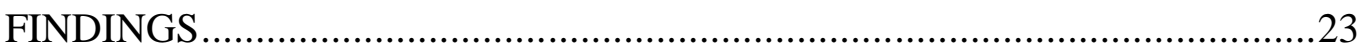

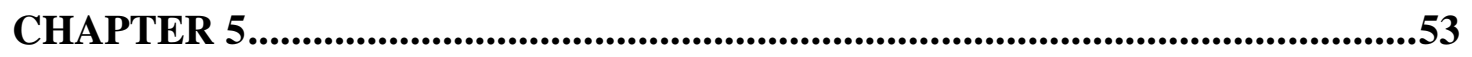

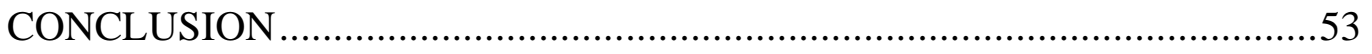

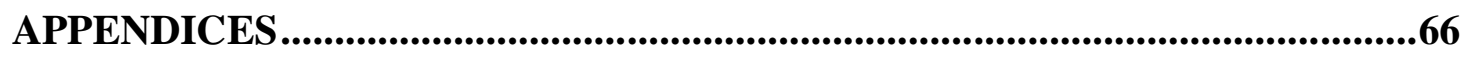

BIBLIOGRAPHY .............................................................................................................81 


\section{LIST OF TABLES}

$\begin{array}{lll}\text { TABLE PAGE } & \text { PAT }\end{array}$

Table 1. Demographic information about study participants..................................64

Table 2. Demographic information about study participants continued..........................65 


\section{LIST OF APPENDICES}

APPENDIX

PAGE

Appendix A. Recruitment Advertisement........................................................66

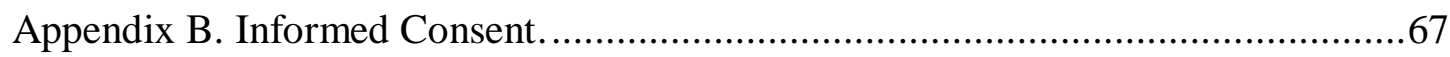

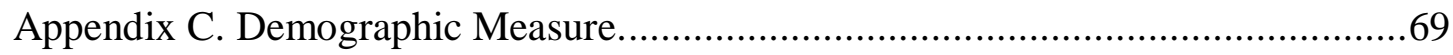

Appendix D. PTSD Checklist - Civilian Version. ............................................... 71

Appendix E. Beck Depression Inventory - II.......................................... 73

Appendix F. Semi-structured Interview Guide............................................... 77

Appendix G. Domestic Violence Resources. ............................................ 80 


\section{CHAPTER 1}

\section{INTRODUCTION}

Historically, research on intimate partner violence (IPV) has focused on heterosexual couples where the male partner was seen as the "batterer" and the female partner as the victim and is defined as "a pattern of behavior where one intimate partner coerces, dominates, or isolates another intimate partner to maintain power and control over the partner and the relationship" (NCAVP, 2014). In recent years attention to same sex couples has highlighted that same sex domestic violence (SSDV) is not only a common occurrence, but is a serious concern in the LGBT community (NCAVP, 2014). Existing research, though adding to the knowledge base on SSDV, often relies on theory and methods for understanding LGBT relationships based on heterosexual couples, thus informing treatment from biased frameworks. The current study seeks to investigate IPV within women's same sex relationships based on a qualitative assessment of the dynamics within these relationships that encourage abusive exchanges. The primary aims of the study are to evaluate the types of violence women experience in the context of a same sex relationship, understand the ways in which women view control and/or power as influencing the perpetuation of violence, and the extent to which control and power dynamics change who the perpetrator and recipient of the violence is over the course of the relationship. 


\section{CHAPTER 2}

\section{REVIEW OF LITERATURE}

\section{Establishing Prevalence Rates}

The struggle to recognize LGBT issues began prior to the 1970s, when same sex attraction was pathologized and criminalized. With respect to IPV, "private" matters in relationships (e.g. partner abuse, marital rape) were not recognized as public policy issues even in heterosexual couples, resulting in SSDV being doubly ignored (Baker, Buick, Kim, Moniz, \& Nava, 2013). Although for many years same sex relationships were excluded from the study of domestic violence, there is a growing recognition of the importance of examining domestic violence in same sex relationships (Baker, Buick, Kim, Moniz, \& Nava, 2013). The 2013 National Coalition of Anti-Violence Project (NCAVP) Intimate Partner Violence Report assessed incidence of violence and homicides in LGBTQ and HIV-affected communities in 17 states found the highest percentage of IPV occurred in LGBTQ people of color, and bisexual and lesbian women (NCAVP, 2014). Specifically, bisexual women experienced higher rates of injury, sexual and physical violence in intimate partnerships (NCAVP, 2014). Goldberg and Meyer (2013) conducted a study of lifetime and one-year prevalence rates among sexual minorities recruited from the California Health Interview Survey and found that bisexual women had the highest rates across all forms of IPV (along with gay men), but that $95 \%$ of abusive incidents were with a male partner. This is significant for screening and intervention purposes as 
there may be a threat from either an opposite or same sex partner. Another recent study conducted by the Center for Disease Control and Prevention on SSDV found nearly 1 in 3 women in the United States has been pushed, shoved, or slapped by an intimate partner and $24.7 \%$ of women have experienced severe physical partner violence (Black et al., 2011). These studies unfortunately only focus on physical violence, sexual abuse, and stalking, which neglect other more prevalent types of IPV, such as psychological violence. IPV research on LGB women from the past two decades estimate perpetration and victimization of psychological abuse rates range from 3-97.6\% depending on how violence was defined, measured, and time constrained (see Mason, Lewis, Milletich, Kelley, Minifie, \& Derlega, 2014 for review). Samples from these studies were typically small $(\mathrm{n}<150)$ and included women recruited through small convenience samples, which can result in biased prevalence rates (Meyer \& Wilson, 2009). While previous studies with small, regional samples can be helpful in informing the literature on SSDV, the lack of sophisticated methodological approaches to reach participants on a nationwide level and solicit greater sample sizes limits the degree with which prevalence data can be established (McClennen, 2005).

\section{Assessment Issues and Limitations}

Most assessment instruments for IPV were developed to understand heterosexual relationships and are primarily useful in quantifying the types of abuse experienced (e.g. Conflict Tactics Scale, Psychological Maltreatment of Women Inventory) (Mason et al., 2014; Ristock, 2003). Even reviews of assessment issues often neglect sexual minorities (Follingstad \& Ryan, 2013), though issues cited as 
problematic appear to be applicable to SSDV: a lack of normative data on what relationship behaviors are harmful, limitations of self-report data that do not include the context of abusive behavior, and a lack of psychometrically sound measure that adequately capture behaviors involved in perpetration and victimization (Mason et al., 2014).

Mason and colleagues (2014) conducted a review of studies assessing psychological abuse and found many of these issues to be true. Authors reported that the CDC has published a collection of assessments in an attempt to standardize IPV measurement, though few of the psychological abuse measures included items developed especially for sexual minorities or LGB participants in measurement development samples. Additionally, sexual orientation was broadly defined and often no distinctions were made between gay, lesbian, and bisexual participants, creating subsequent problems comparing results across studies. Timeframes and relationship histories were also inconsistently defined across studies. Participants may be asked about abuse in the past year, past 5 years, their current relationship, or past relationships and their partner's gender identity is not requested. The assumption is that SSDV is occurring when in actuality participants may or may not have experienced abuse with a same sex partner. Lastly, Mason and colleagues (2014) found that victimization was assessed more than perpetration. Various scales and assessments ask about psychological IPV in terms of whether or not it occurred in the relationship without specifying who the perpetrator is, making it difficult to make inferences about dynamics within the relationships (Mason et al., 2014). Again, as with relationship histories, no attention was given to the gender identity of the 
participant's partner. Prior studies have validated psychological and physical IPV with LGB populations using measures created for heterosexual couples such as the Conflict Tactics Scale and Psychological Maltreatment of Women Inventory using gender neutral language, though there are no measures validated for sexual SSDV (Balsam, Rothblum, \& Beauchaine, 2005; Balsam \& Szymanski, 2005; Dank, Lachman, Zweig, \& Yahner, 2014; Landolt \& Dutton, 1997; Matte \& Lafontaine, 2011). Nonetheless the inconsistent methods used to establish prevalence rates across studies has led to a wide range of IPV estimates in LGB women (West, 2002).

Assessing context is another barrier to understanding relationship dynamics from quantitative measures. Assessments often do not allow respondents to distinguish between violent tactics to control or for self defense, and lack context for vague wording (Baker, Buick, Kim, Moniz, \& Nava, 2013). For example, an item asking if your partner "hurt" you could be interpreted as a slap or physical injury, depending who is asked. LGB specific constructs are needed as well, to capture specific experiences of same sex couples, such as stigma, internalized homophobia, and behaviors including threats to out a partner's sexual orientation to others (Balsam \& Szymanski, 2005). Similarly, attention to participant recruitment methods is important to generalizability of research findings. Sexual minorities have historically been a challenging group to recruit due to many factors, including accessing individuals who are not out, stigma identifying oneself as LGBT, and locating large representative samples (Meyer \& Wilson, 2009). Using LGBT community venues (e.g. pride events, nightclubs), social media, and snowball sampling can result in a sample of individuals who may be similar on a number of characteristics associated with the recruitment 
methods that are cannot be accounted for in the data analysis stage (Meyer \& Wilson, 2009). Therefore cultural/regional differences, motivation to participate in research, and access to requests for participants are all of greater concern, particularly with SSDV research. All of these concerns prevent fair comparisons between studies about the actual rates and correlates of SSDV and can make developing theories difficult. With disparate information being reported at the most basic levels of SSDV, investigating deeper understandings into the dynamics of women's same sex relationships can become increasingly challenging.

\section{Explanations for Same Sex Intimate Partner Violence}

Theoretical issues. As seen in the issues related to measuring IPV in same sex relationships, many domestic violence theories were developed to understand heterosexual relationships. For example, the family violence theory maintains that an imbalance of power in the family encourages male-perpetrated abuse against women, which was furthered by the feminist perspective which acknowledges the influence of patriarchy in partner violence (Blasko, Winek, \& Biesehke, 2007). One traditional explanation of domestic violence postulates that violence is legitimized by the partner who has the most power, which is combined with the social expectations of men and women. These prototypical frameworks establish that the man is the perpetuator and the woman is the victim. This gendered construction of power difference makes an understanding of SSDV difficult, potentially leading therapists to make biased assumptions about the dynamics in violent relationships and may lead to inaccuracies during assessment (Blasko, Winek, \& Biesehke, 2007). Brown (2008) argues that heterosexism against same sex couples results in limited beliefs about who can and 
cannot be a victim of IPV. Furthermore, individuals who are already subjected to the view that same sex partners are physically and socially matched in terms of power find that the abuse they experience is trivialized, the responsibilities of the abuser are downplayed, and victims fail to report incidents due to self blame (Brown, 2008).

Unique relationship dynamics. Baker and colleagues (2013) call for an ecological framework to understand same sex partner violence, such that context is considered and thought of as a dynamic and multilayered process. For example, on a macro level men have historically had greater power in heterosexual relationships in Western culture due to greater economic, social, and political control. Greater power has the potential to legitimize violence as an appropriate way to resolve conflict (Baker, Buick, Kim, Moniz, \& Nava, 2013). Though this explanation has generally been appropriate to conceptualize IPV within heterosexual couples, it does not neatly translate to same sex IPV or female to male perpetrated violence. Therefore attention to the specific contexts present in women's same sex relationships must be uncovered to illuminate the dynamics that may lead to IPV. Researchers have found that the presence of IPV across sexual orientations may reveal unique gender aspects that contribute to same sex partner violence. Balsam and Szymanski (2005) found that women who adopted a femme identity were more likely to experience a higher lifetime prevalence of LGB-specific forms of aggression, which may be related to research that femininity is rejected in the lesbian community and butch/androgynous presentations are more valued (Zipkin, 1999). McKenry, Serovich, Mason, and Mosack (2006) found in a sample of gay men and lesbian women that reported higher masculinity characteristics was related to a greater inclination to use aggression to 
solve relationship problems. Participants who perpetrated violence also indicated they experienced greater relationship stress and were insecurely attached to their partners (McKenry, Serovich, Mason, \& Mosack, 2006). These findings suggest that in an attempt to control one's partner, in same sex relationships, violence may be facilitated when at least one partner exhibits high levels of dependency and attachment. When individuals feel disempowered due to these personal characteristics or dysfunctional aspects of their intimate relationship, they may resort to violence as a means of influence (McKenry, Serovich, Mason, \& Mosack, 2006). Thus for women's same sex couples, women exhibiting more masculine gender roles and/or developing less secure attachments with their partners may be more likely to perpetrate violence.

Aside from attachment and gender based explanations, power dynamics can emerge from identity-related factors as well. Intertwined into the contextual issues within same sex relationships with partner violence are cultural issues, particularly in the form of minority stress and internalized homophobia (Balsam \& Syzmanski, 2005). The stigma of one's sexual orientation intersecting with other minority identities such a race, ethnicity, socio-economic status, and religion may also create additional power differentials that may contribute to violent incidents between partners (Baker, Buick, Kim, Moniz, \& Nava, 2013). The disparity in power due to cultural differences appears to be a trend present in many violent same sex couples, as more IPV is associated with greater demands for obedience from the abusive partner, power imbalance, and inequality when making decisions related to sex, the relationship, and social behaviors (Eaton et al., 2008; Stevens, Korchmaros, \& Miller, 2010; West, 2002). Women who are inexperienced may be especially vulnerable to 
these pulls from those romantic partners who are more comfortable and experienced in same sex relationships.

Ristock (2003) found in a qualitative study of lesbian IPV that women reported violence often happened in their first relationship, where in a desperate attempt to find a partner, they remained in abusive situations because women feared they would not find someone else. The social context of "coming out" or revealing their same sex attraction to others, also left many of the women in vulnerable positions and so were at the mercy of the abusive partner to stay connected to the LGBT world (Ristock, 2003). This study also discovered, like many heterosexual relationships, lesbians experience predictable cycles of violence where there is a clear perpetrator and victim between periods of calm (Ristock, 2003). Alternatively, women also reported fluctuating power dynamics where at different points either partner could be the perpetrator of violence (Ristock, 2003).

Power dynamics. As has been seen in the research on heterosexuals, power imbalances that encourage partner violence are generally associated with factors related to American patriarchal society (e.g. gender role socialization, wage inequalities, and greater childcare responsibilities for women) (McClennen, Summers, \& Daley, 2002). Prior studies have found power imbalances are also strongly correlated to lesbian partner violence, but have not included the specific situational, social, or relationship-based contexts that facilitate IPV (Hart, 1986; Renzetti, 1992). There is little consensus among social scientists about definitions of power in close relationships or its relation to gender (Jenkins, 2000). Social psychologists define power as influencing others' behavior unilaterally by controlling their outcomes or 
resources, while the sociological view includes various forms of structural power afforded through institutions (Jenkins, 2000). Structural power legitimizes greater authority and influence for certain social statuses over those individuals who are structurally less powerful by virtue of their given roles in society (Jenkins, 2000). The field of communications discusses the power in terms of linguistic devices which may also be used to further manipulate one's partner in order to change the perception of the abuse that has occurred and to portray the perpetrator in a less negative light (Cahn, 1996). For example, blaming abusive on alcohol or claiming that the victim was not "hit" but rather was "shaken" can shift the responsibility and attempt to recount events in a more socially acceptable fashion.

In a mixed methods study of lesbian IPV, Renzetti (1992) found power imbalances are one of 5 contributing factors to lesbian abuse and defined power in terms of 4 factors (personal characteristics, feelings/patterns of interaction, sources of conflict/strain in relationship, status differential). The strong influence of power dynamics on lesbian IPV has lead to the creation of an assessment measure to assist providers. McClennen, Summers, and Daley (2002) developed a scale to measure power imbalances in lesbian couples and revealed 6 factors of power that emerged in their scale: communication and social skills, substance abuse, intergenerational transmission of violence, fakes illness, internalized homophobia, status differentials. Authors found these factors to be consistent with correlates of IPV in previous research, which helps providers to consider and incorporate specific contextual information that is relevant to women's same sex couples. The limited research beginning to understand the dynamics of same sex partner violence provide a number 
of explanations that can help to inform assessment and treatment. Current studies must work to evaluate the extent to which these various patterns can be generalized in some way to the experience of women same sex IPV such that professionals can appropriately assist each partner.

\section{Implications on Practice}

Provider obstacles to assessing LGB women. Across disciplines including physicians, nurses, emergency room doctors, dentists, and community health center staff, providers have shown difficulties assessing for and intervening with same sex couples, despite the number of risk factors known to be related to LGB women's IPV (Ristock, 2001). Some barriers to assessing for IPV relate to problems on an institutional level. To highlight the complexities that arise when assessing IPV, Ristock (2003) conducted focus groups with 45 feminist service providers who reported organizational mandates required their agencies to work with the "victim," who often is defined as the person who did not start the violent incident or the partner who has never used violence, even in self defense. Service providers in the study spoke to the difficulties this creates among women seeking services because identifying the victim/perpetrator is a complex process. Professionals may also avoid conducting assessments when there is no systematic protocol in the organizational structure detailing how to handle reports of IPV (Hamberger \& Phelan, 2006; Waalen, Goodwin, Spitz, Petersen, \& Saltzman, 2000). Similarly, because the existing resources are primarily developed for heterosexual individuals, providers are often need to make exceptions on an individual basis because nothing available only for 
LGB women perpetrators, even less so for LGB Spanish speakers and people of color (Merlis \& Linville, 2006).

The lack of awareness about SSDV and factors that influence lesbian relationship dynamics can lead to fewer women obtaining help. Gender presentations (e.g. butch/femme roles), high levels of relationship fusion, and the influence of (internalized) homophobia may be related to IPV but are often overlooked if providers are not aware of their importance. Providers may not know what to focus on during an assessment, given the complexities in lesbian relationships (e.g. racist verbal remarks versus physical attacks) (Ristock, 2003). Relying on discourses of male-perpetrated violence and gender role stereotypes often prove to be unhelpful because those patterns do not always translate to women's same sex couples when traditional indicators of abuse are not present (Ristock, 2003; Seelau \& Seelau, 2005). Compared to providers of services to heterosexual couples, service providers for lesbian couples are less likely to address non-physical abuse (Blasko, Winek, \& Bieschke, 2007). Further when providers feel more confident that physical abuse is present, they are more comfortable with taking the woman on as a client (Basow \& Thompson, 2012; Blasko, Winek, \& Bieschke, 2007). This has negative implications for lesbian women, particularly if physical aggression is not present. In general, insufficient knowledge and resources in domestic violence organizations and providers can often prevent women from seeking help.

Barriers to help seeking for LGB women. Women frequently encounter barriers when attempting to end abusive same sex relationships. Although in some instances the LGBT community can provide individuals with support, many LGBT 
individuals minimize and deny the existence of SSDV thus perpetuating silence among victims (Balsam, 2002). The desire to protect and maintain the idealized vision of the supportive, safe, and non-violent lesbian couple is a strong motivator to remain silent, which is reinforced by the other cultural, social, and institutional forces that discourage women from speaking out about abuse (Hardesty, Oswald, Khaw, \& Fonseca, 2011; Merlis \& Linville, 2006). Many abusers are aware of the confusion around same sex domestic violence and manipulate law enforcement by playing up the "feminine victim" role to get the other partner arrested for defending themselves (Hassouneh \& Glass, 2008). This begins a long process of hiding abuse because women feel as though any attempt to report IPV will be misconstrued, which leads to being isolated from social networks, making it increasingly difficult to seek help (Hardesty, Oswald, Khaw, \& Fonseca, 2011). The decision to report abuse for LGB women also elicits fears of anticipated negative consequences (e.g., losing custody of children, their name is not on the lease) by speaking with various professionals (Hardesty, Oswald, Khaw, \& Fonseca, 2011; Oswald, Fonseca, \& Hardesty, 2010). Women often feel rebuffed by formal sources such as attorneys and shelters due to homophobia and that therapists perceived as unhelpful or therapists may contribute to them being ashamed or re-victimized when they minimize abuse and conceptualize violence as mutual experience between codependent partners (Hardesty, Oswald, Khaw, \& Fonseca, 2011; McClennen, 2005; Oswald, Fonseca, \& Hardesty, 2010; Poorman, 2001). Similarly, racist acts and threats to expose one's immigration status that are present in the relationship, also prevent LGB women from seeking help if they believe professionals will not be sensitive to these experiences (Mendez, 1996). In 
extreme cases, LGB women experienced aggressive treatment, threats, and intimidation from police, often feeling they were treated marginally better than abusive partners acted towards them (Alhusen, Lucea, \& Glass, 2010).

The current study seeks to elaborate on previous findings on the relationship and power dynamics that contribute to women's same sex IPV. Results are expected to inform assessment and intervention such that providers can offer services necessary for the unique experience of LGBTQ individuals engaging in partner violence. The following research questions are informed by the aforementioned literature review:

1. How do women in same sex couples describe physical, psychological, and sexual violence and abuse in their relationships?

2. How do women describe the roles that power and dependence played in their abusive relationships and, do they describe it as changing over time?

3. To what extent does abuse/violence change over time within their relationship or influence the presence of abuse in subsequent relationships? 


\section{CHAPTER 3}

\section{METHODOLOGY}

\section{Research Design}

This study was conducted using qualitative interview methods to explore the relationship and power dynamics within women's same sex partner violence. Before women were asked to provide retrospective accounts of partner violence, they were screened through an electronic survey that included an assessment of demographic information and the severity of current trauma and depressive symptoms, and also introduced to the nature of the interview portion of the study. Participants whose trauma and depressive symptoms were within reasonable and minimally distressing limits were contacted via email to set up a telephone interview time. Individuals' symptom scores that fell into a severe range were thought to be more likely to become overwhelmed by participating in a study where they would be asked to detail an already upsetting topic. Interview data was analyzed through content analysis to determine common descriptions across the participants' accounts, as they aligned with the three research questions.

Within same sex couples where IPV is present there is a great deal of heterogeneity that can best be illuminated through qualitative research (Ristock, 2003). Therefore qualitative methods are needed to explain and describe the dynamics that occur in LGB abusive couples. Qualitative interviewing, particularly with survivors of IPV, allows for respondents to describe their experiences flexibly and 
with rich detail. There is also an emphasis on a non-judgmental understanding of the individual's experience (Bornstein, Fawcett, Sullivan, Senturia, \& Thornton, 2006). The difficulty with accessing this population and the lack of knowledge about women's experiences of same sex domestic violence may be well matched with the smaller sample sizes allowed for qualitative research (Singh \& Shelton, 2011).

\section{Sample}

Participants were recruited through the snowball, or chain, sampling procedure where informants and participants are asked to forward the survey link to other women who would be eligible. Eligible participants were required to be at least 18 years old, identify as female, be able to read English at a 5th grade reading level, and selfidentify as an individual who experienced partner abuse or domestic violence with another female-identified partner. Participants were not required to identify as a particular sexual orientation, as women may engage in intimate relationships with other women while not necessarily using the label gay, lesbian, or bisexual. Similarly, participants were not required to identify as a perpetrator or victim, though they were required to identify as having experienced violence with a partner. Special attempts were made to recruit women from diverse racial and ethnic backgrounds, thus pointed efforts were employed to solicit potential participants through online groups, listservs, historically Black colleges and universities, social media sites, and online advertising in racially diverse cities that were also likely to be LGBT friendly (e.g. New York, Atlanta, Miami).

\section{Measures to Describe and Screen the Sample}


Demographic measures, post-traumatic stress, and depression questionnaires will be administered electronically during the first stage of the study used to recruit and screen participants. The semi-structured interview was conducted over the phone with eligible participants.

Demographic measures. Descriptive information was analyzed for this sample including age, race, ethnicity, gender, sexual orientation, current relationship status, highest level of education, employment, and if the participant had sought counseling or other services for a relationship concern.

Post-traumatic stress. Post-traumatic stress (PTSD) was assessed using the PTSD Checklist (PCL), a self report measure reflecting the DSM-IV criteria for PTSD (Weathers, Litz, Herman, Huska, \& Keane, 1993). The civilian version, PCL-C, asks about symptoms related to stressful life experiences that could be based on the degree of distress from multiple traumas experienced over the time period of one month. The PCL-C contains 17 items which are rated on a scale of 1 not at all to 5 extremely. An example of an item: "Feeling very upset when something reminded you of a stressful experience from the past?" A total symptom severity score is obtained by summing all items, ranging from 17-85. A suggested cutoff score of 30 or higher indicates presence of PTSD. The PCL has shown to be psychometrically valid and reliable, with alpha ranges of 0.77-0.93 and 0.94-0.96, respectively (Orsillo, 2001). For the purpose of screening and eligibility, participants were eliminated if their PCL-C score was above the range of 30-35 at the time they completed the online survey.

Depression. Depressive symptoms were assessed using the Beck Depression Inventory - II (BDI-II), a 21 item self report measure reflecting the DSM-IV criteria 
for Major Depressive Disorder (Beck, Steer, \& Brown, 1996). The items address symptoms including changes in sleep, changes in appetite, sadness, and irritability, with scores ranging from 0 not present to 3 severe for each item. Scores range from 063, with higher scores indicating more severe depressive symptoms. Four cutoff points also indicate severity of depression: 0-13 minimal; 14-19 mild, 20-28 moderate; 29-63 severe. Authors report an internal consistency of 0.91 (Beck, Steer, \& Brown, 1996). For the purpose of screening and eligibility, participants were eliminated if their BDIII score was equal to or above 29, the beginning of the cutoff range for severe depressive experience.

Semi-structured interview. The semi-structured interview was administered via phone to participants who had completed the quantitative measures and did not score in severe distress levels. The purpose of the semi-structured interview is to obtain information regarding the nature of the abusive acts the participants experienced and the role power played in their relationship. The semi-structured nature of the interview will ensure all participants receive the same questions prepared in advance in an interview guide focused around the topic (Polit \& Beck, 2008) The interview guide also included additional prompts to help elicit more specific information related to the content area in the main question and were used with all participants to better understand their experiences (Appendix F).

\section{Procedure}

Participants were recruited through a chain sampling method where solicitation advertisements were sent to domestic violence organizations, listservs dedicated to LGBT and/or women's concerns, and social media groups. Potential participants were 
also encouraged to forward the advertisement to other women that might be eligible. The advertisement contained a survey link for the initial screening survey and consent materials. Women who consented to completing the initial survey answered demographic questions, as well as screening measures to assess the degree to which they currently experience traumatic and/or depressive symptoms. Following the screening measures, participants were provided with a brief description of the nature of the interview portion of the study regarding women's experience of abuse or violence with a same sex partner and a list of national resources for domestic violence.

After participants completed the survey, their PCL-C and BDI-II scores were calculated to evaluate their level of distress at the time of the survey. Initial contact with participants occurred via email through a private study account designated specifically for correspondence with participants. Ineligible participants' scores indicated current severe distress and were contacted via email with resources for domestic violence, as well as their status in the study. Eligible participants, who did not receive scores indicative of current distress, were contacted via email to set up a time to discuss the study and schedule the phone interview. During the initial phone call, all participants were consented again and provided with a description of the study. Participants were informed that their involvement in the study is voluntary and they could discontinue the study at any time. Once participants confirmed their participation, they completed the phone interview during the initially scheduled phone call. Phone interviews allow the interviewee the feeling of greater anonymity that would not be afforded by face-to-face interviews. This is especially relevant for sensitive subjects and is beneficial in accessing hard-to-reach populations (Sturges \& 
Hanrahan, 2004). While telephone interviews do not provide interviewers with visual cues of the participants, attention to verbal cues can be utilized and still result in participant responses comparable to face-to-face interviews (Sturges \& Hanrahan, 2004). Process consent was also provided as needed if distress occurs during the interview. Interviews ranged from 45-90 minutes in length and were completed in one session. Once the interview was completed, participants received resources to manage any potential distress and were contacted after two weeks to follow up regarding their discussion of sensitive topics.

\section{Data Analysis}

Quantitative data was analyzed descriptively to understand the demographic and psychological characteristics of the sample. Qualitative data preparation included the transcription of the audio data and analyzation through content analysis based on each of the three research questions. Content analysis is defined as a systematic and dynamic approach for analyzing verbal data (Graneheim \& Lundman, 2004). Data is broken down into smaller units, coded, and then grouped together under shared concepts (Graneheim \& Lundman, 2004).To prepare data for analysis, research assistants transcribed interviews from their associated audio files for each participant and all identifying information was removed. Each transcript was subsequently checked for accuracy by the interviewer before finalization. Transcripts were then assigned to one research assistant and the interviewer for analysis. Each text was read through several times to obtain a sense of the whole interview. Next, meaning units, or phrases and sequences of sentences, were labeled with a code to summarize the description of the text given the context of the topic area. Analysis was focused on 
manifest content, or sole consideration to the visible and obvious components that did not require further interpretation into the deeper meaning into the data. Differences in codes were reconciled between the double coders until 100\% agreement was achieved. Participants' coded experiences around a similar topic were extracted and categorized in order to draw broad conclusions across the entire sample (Graneheim \& Lundman, 2004).

Trustworthiness. Lincoln and Guba (1985) identified the appropriate criteria to be used for research within qualitative research to establish trustworthiness of data. Trustworthiness depends on the credibility, transferability, dependability, and confirmability of data. Each criterion has a series of activities that increase the probability that trustworthiness will be established, with some special considerations to internet qualitative methods (Aselton, 2012). Credibility refers to the ability of the description to reflect the experience of the participants and readers who may share their stories (Graneheim \& Lundman, 2004). To ensure this, it was important to screen appropriate participants whose experience was in line with the research topic and maintaining prolonged engagement by interacting with IPV survivors across several months (Beck, 1993). Credibility can also be established through peer debriefing meetings with an experienced qualitative researcher to help triangulate the findings and conducting member checks with informants that are knowledgeable about IPV and/or same sex couples (Beck, 1993). Research assistants and the researcher engaged in regular online meetings to discuss issues during the analysis phase and distress around the topic content. A consultant was also utilized to provide ongoing feedback and resources to improve analysis. Transferability refers to the extent that findings can 
be generalized to other similar populations (Beck, 1993). To facilitate transferability, clear and distinct description of the culture, context, selection, and characteristics of the participants is necessary (Graneheim \& Lundman, 2004). Dependability and confirmability are concerns that extend from the proposal to presentation of results. They require both methods and findings be clearly executed to enhance their ability to be replicated over time (Aselton, 2012). Confirmability is also concerned with the objectivity and neutrality of the data (Beck, 1993). Each of these was established by creating an audit trail detailing the process of transferring email data to transcripts, engaging in inter-rater agreement of codes and categories, as well as establishing and utilizing an interview schedule with each participant. Maintaining reflective notes will allow for personal reactions and experiences to be documented to prevent biases and interference with data analysis (Beck, 1993). 


\section{CHAPTER 4}

\section{FINDINGS}

\section{Demographic and Contextual Data}

In total, 100 women accessed the initial online survey used to recruit participants. Of those, 53 women completed some portion of the demographic information and symptom screeners. Three women were deemed ineligible after indicating they did not experience IPV. Twenty women received symptom scores below the severe range cutoffs and completed demographic information; given their eligibility for the study, they were contacted via email to schedule the phone interview. Another twenty women found to be ineligible were eliminated due to elevated PCL-IV and/or BDI-II scores; this subgroup tended to be college educated $(n=9)$ or have an advanced degree $(n=8)$ and be employed part time $(n=9)$ or full time $(n=9)$. Ineligible participants who provided a working email were contacted with information that they were not chosen for the interview phase and were given supportive resources. Thirteen women agreed to participate in the interview portion, though one woman dropped out of the study at the time of her scheduled interview due to unforeseen distress.

The sample consisted of 12 female-identified participants. Participants' ages ranged from 20-71, with a mean age of 37.67 ( $\mathrm{SD}=15.58)$. Most women identified their gender as female or woman, with three women identifying as no-op transsexual, gender-fluid, and gender non-conforming, respectively. The women tended to also 
describe their sexual orientation as lesbian, with two participants identifying as bisexual and one as gay. The sample was generally well-educated and had achieved a college $(n=2)$ or advanced degree $(n=8)$, and was employed at least part time $(n=10)$. The racial/ethnic breakdown was as follows: white $(\mathrm{n}=8)$, Black $(\mathrm{n}=2)$, and white/American Indian multi-racial $(\mathrm{n}=2)$, with two also identifying as Latinx. Participants were also asked if they had engaged in psychotherapy related to their experience of domestic violence for which eight women endorsed individual or couples therapy. Complete demographic information for the sample is presented in Tables 1 and 2 with corresponding pseudonyms associated with each individual to protect confidentiality.

Through the course of interviewing, the women revealed important contexts for the abuse they experienced with their partners. Eight women indicated their first abusive relationship occurred within their first ever same sex partner or first serious relationship with a same sex partner. One woman reported her first abusive relationship was with her second serious relationship with a woman. The number of abusive relationships ranged from 1-4, with nine having one experience and three having either two, three, or four abusive relationships, respectively. Additionally all three of participants who noted they had multiple abusive partners, indicated that at least one of those relationships was with a man.

\section{Qualitative Findings}

\section{Description of Abuse}

The first research question sought to understand how women in same sex couples describe physical, psychological, and sexual violence and abuse in their 
relationships. All twelve noted that abuse tended to begin early in the relationship and/or when they moved into the same living space with their partner. It is noteworthy that participants often felt that their experiences of abuse were complicated by their own mental health or that of their partner. Factors included alcohol abuse $(n=7)$, preexisting psychiatric diagnoses $(\mathrm{n}=5)$, prior childhood sexual/physical abuse and harassment $(\mathrm{n}=8)$, and history of self-harm/suicide attempts $(\mathrm{n}=7)$. These issues were often used to justify abuse, rationalize their partners' behavior, and maintain toxic relationships despite experience of violence.

All women reported an experience of psychological abuse and manipulation that occurred in the first stage of violence.

Robin: I mean, everything was going good, I mean in the beginning of our relationship, then we moved in together and that is when it really got bad. I mean emotional abuse, making me feel like I wasn't good enough... you know, the way I dressed. She would always put me down that way, and I mean she would always treat me like I was her maid, and if I didn't do it she would get mad and start yelling.

Dawn: It's stupid little things that you realize later, I'm sure you've heard this...but I was not allowed to sing in the car, because it was annoying to her. I could hum, but softly and to myself. And I was not allowed to sing in the car even if she was sleeping. If she woke up and I was singing, she would snap at me. And the final really insulting thing that she ever said to me was she told me she hadn't been attracted to me for about 6 months. This was right before the divorce that she actually said that to me.

Gail: Now I'm noticing, you know that's she was very manipulative. And then about a year and a half in it was still mainly emotional, verbal stuff but, it was, it really escalated and then she would also like block me from leaving. She would just say things to put me down. It would generally, she would get angry with me for something which, in my mind was usually very small things, and I would try to talk to her and then she'd yell at me but when it, when it got the worst, was when she would drink. 
Nora: And even to the point where she would say things like, I guess some of it was even a little bit racial, cause she was Black and I'm Black, but she said that some of my interests were not pro Black enough.

Irene: There was a lot of just emotional stuff. Telling me I could never find anyone better. You know, how could I do this to her, why wouldn't I, you know spend all my time with her. She tried to convince me to drop out of school like, like high school. Drop out to spend all of my time with her.

Nora described how her partner continued to harass her after their relationship ended.

Despite seeking assistance from law enforcement, Nora's experience was misconstrued as mutual abuse.

It kind of died off a little bit and then it got back up. She somehow found out that I was seeing someone else and it started all back up all over again. And I tried to get a restraining order and the judge was like "it looks like you guys are doing this to each other." I'm scared for my life, because I didn't think I had proof of that but I don't know, if it was because of the way I told the story. This happened for longer than we were ever dating that she was harassing me.

Many women $(\mathrm{n}=10)$ also endorsed physical abuse and/or threats of physical

violence from their partners.

Sarah: It was lots of name calling and derogatory comments and along with physical violence. Yeah she would threaten me. I mean, throughout the time she went after me with a knife a few times.

Irene: There was physical violence there. Slapping, pushing, like holding me up against the wall to keep me from leaving.

Nadine: She got physical and she told me like "if I can't have you then no one will" and she put a pillow over my head and like tried to suffocate me. And then she grabbed a belt and tried to put it around my neck and there was nobody home.

Two women reported that they retaliated against their partner in a one-time incident; they did not identify their actions as abusive and expressed immediate regret that they had engaged in these behaviors, regardless of their circumstances. 
Ellen: So there was one time when we were fighting and I did grab her arm, but it was only for like a second. And she was much bigger than me and I couldn't have actually restrained her. But yes I did physically touch her, but I didn't hurt her. You know what I mean? It didn't hurt; I grabbed it but I didn't scratch her or leave a mark or anything. And so I think that she in that time tried to make me feel like I had made her afraid. But like she outweighed me by like quite a bit and was much stronger than me, so I couldn't have actually, I wouldn't have actually hurt her. Also she wasn't really in danger from me grabbing her arm for a second.

Karen: I never knew what was going to happen or when. And one time she came after me and I actually swung back. And that was the last time I ever had a problem [with her]. I didn't hit her - I went outside and got sick. That's how far I was pushed. Yeah, it was totally against my nature, but I couldn't take it anymore. I snapped and literally, I don't remember. It was literally a blackout moment where I swung at her, got on the floor, and I got back up to really nail her one and a friend called my name and snapped me out of it. And I realized what I had done. Like, I ran out of the building and threw up, I was so upset.

Nadine admitted to using physical violence during a one-time incident with her

partner, after being pushed to her limits in the middle of an argument.

It was not self-defense. She didn't really talk, she didn't acknowledge me, she was just kind of like laying there and I would ask her questions or say things that warranted a response and she wouldn't give them to me and I was just like really frustrated. I was sad, I was angry, and so like I was yelling and I was hitting her. While I was doing that, she just grabbed me so I couldn't continue to hurt her, because she was actually really strong. So I didn't do any harm to her, but I know that my intention was to hurt her because I wanted her to respond somehow or another.

One third of women indicated that their partners threatened their loved ones, pets, or themselves $(n=4)$.

Betty: Well I mean we did have a dog that was terrified of her so it wasn't like she was threatening the dog but it was a big issue for me. No, I mean much more towards herself, I mean it was much more being afraid that if I left her she would kill herself or she wouldn't be able to make it or, you know, but not to other people so much.

Lauren: No just herself. No she would never, never have threatened to hurt me or my cat or anything and she felt so like awful and guilty after she accidently hurt me that, like that I think was the closest she really got to doing something to herself because she felt so ashamed. 
Three women reported that aside from physical abuse, their experience of sexual abuse and coercion was the most disturbing act committed against them from their partners.

Robin: I guess kind of, I mean, we really hadn't had, you know, a lot of intimacy. So I guess she was trying, and umm, I just told her no, but she just forced it on me anyways. The worst thing was she came home late one night, drunk, and she molested me.

Ellen: She would kind of like push my boundaries sexually, but not, I wouldn't say it was rape. She was just like, I don't know what it was. It was not respecting of what I wanted.

\section{Power and Control Dynamics}

The second research question explored how women describe the roles that power and dependence played in their abusive relationships and if they describe it as changing over time. Participants explored the varied areas where power impacted the relationship or where one party felt a sense of control over the other. For all participants discussion of relationship concerns resulted in imbalance of power such that participants became passive in interactions with their partner and avoided initiation of important topics ( $\mathrm{n}=12)$. Alternatively, their partners blocked communication by being argumentative, aggressive, or dismissive.

Robin: In the middle of an argument she would look at me like I was stupid. That's how it would always go. And then I would just agree with her. If she had an issue with me? She would tell me about it and then I would have to, I guess, fix myself.

Ellen: Well we would probably argue about it and maybe be angry and then, like sometimes when we had big arguments she would like refuse to talk to me for days. I think it was always me bringing stuff up. She was just always angry about everything, like her fuse was super short.

Sarah: If I tried to talk about, you know how I saw things or my perspective, it, it could never, she could never understand it. She couldn't... yeah, it just didn't go anywhere; we just went in circles. Her perspective was the only one that counted and mine was wrong. If it was her thinking I was going to 
abandon her or anything like that, we could not talk about that stuff, you know, rationally.

Ten women described a lack of power in terms of their social life. Participants

expressed that their partner tried to reduce or eliminate contact with friends, family,

and activities the women were committed to before their relationships.

Terry: And so, you know we started dating and we moved in rather quickly and you know looking back on it I can tell all this, she started isolating me and just making my world really, really small. I remember I had one activity. I was the chair of a committee for a LGBTQ center here, and we had a meeting every whatever, once a month. You know it was a specific time, and if it didn't end exactly on time my phone would ring. "Where are you? What are you doing? Why aren't you coming home? Why aren't you home?" And she didn't like it that I did this, because she knew I was meeting people that were other than her, but I did that one thing and it was always pretty precarious about whether I was going to get the call, and I almost always did every time, about where I was which was at the meeting, if it ran long.

Dawn: We would take three weeks and we would drive to go see family... except we would spend three weeks with her family and less than 24 to 48 hours with mine. My family was four hours away. She didn't want to not be with her family if that makes any sense. She said "well I just want to spend time with my family. I guess if you want to go see your family you go right ahead."

Lauren: I think isolating is probably a little bit strong of a word for it. It definitely had the effect of disconnecting me from some of the people I cared about and that I didn't really like but, it certainly never, she would sort of make me feel guilty sometimes for spending time with people other than her. She just made it clear that she didn't really like that and that you know, kind of made me feel guilty for making her feel bad.

Participants reporting a lack of sexual power shared that initiation, types of acts

performed, and frequency were all controlled by their partners $(n=8)$. Furthermore, women who attempted to deny their partners sex or initiate sex with partners who lacked desire were criticized.

Karen: That's where I felt, hindsight is so much for foresight. She was the manipulator and she knew sex would get me to do whatever she wanted. The "I have a headache" was not uncommon. Only if I was ready to turn over in my 
sleep, that was fine, that's when she decided she was going to do something so I didn't go to sleep. She used it as a controlling mechanism.

Nadine: First relationship was mostly completely her decision. The second one, at the beginning I would say it was hers...her decision. But as we got to know each other more like I was more comfortable initiating and saying when and where. I tried being more spontaneous and fun with it, but after the two and a half year mark when she started being so distant and everything, it was mostly left to her because even if I would initiate things or imply things she would not be as into it as she was before.

Nora: She was also really controlling of our sex life. So it was basically like we weren't having any and then I definitely couldn't approach the topic or anything. So all of it was on her terms, like all of it - when and how, whatever.

Seventy-five percent of the sample described financial influences throughout their relationships, such that their partners controlled how money was spent in the household ( $\mathrm{n}=9$ ). Interestingly, of those women, three reported being the primary breadwinner and simultaneously being manipulated for the money they contributed to the relationship.

Nora: She had an inheritance from her grandparents and she was living a little too nice to be in grad school. Like it was a big deal to be going to these fancy places to eat like Red Lobster and spend all this money on food and buying Coach shoes. That's not what I would do. So I feel like she felt she had financial and some kind of mental planning stability over me.

Karen: Even after she got out of the [military] service, I don't remember her working. But, I was the breadwinner; was the echoing of heterosexual relationships. She was just saying how to take things. I went out and did the work. We got to the point where not too long before we went up in smoke, I was working two or three jobs. Not so much for the money, but more for a reason not to go home. But I was the provider. And in my head I had a headline and everything I was doing fine, until all the sudden I realized I wasn't.

Irene: I was in control of the finances, but I also felt I had to do whatever like I had to keep her the most comfortable she could be, so then I wouldn't have to deal with her, you know freaking out. Umm...she wanted me to sell pot so she tried to get me to use my paycheck to like buy a pound of pot so that she could sell it. 
For participants who were not "out" and had not disclosed their sexual orientation to others, partners gained control by threatening to out the participants or telling disapproving family members ( $\mathrm{n}=6)$. Partners also questioned the women's sexual orientation as a test of commitment to the relationship.

Sarah: She thought I was always going to go back to being heterosexual and that I wasn't a lesbian and yeah, she would never believe me or... very strange, yeah. Well like I said, the first year was not like that at all. And then after that it started to change and just continued to get worse.

Gail: If I didn't want to have sex then at certain times she would get angry and then just say things to me that just were...I don't know. She never forced herself on me or anything like that. It was more like if I wasn't in the mood she would be like "oh you don't love me you, don't care about me." You know that kind of thing. So then like, then I would have sex with her, which is not good but I knew like where it would go. And so sometimes I did.

Irene: My family here was religious and like after we broke up she outed me to my mom so I mean it wasn't like a threat of physical harm. She told me not to break up with her and I did and then she forwarded my mom all of our emails. That was pretty terrible. Yeah my family is fundamentalist Christian, so that's a whole different can of worms that I was almost thrown out of my house.

Seven women noted that education and/or intelligence acted as a source of power for them and their partners. Participants perceived their higher education as providing them with increased social capital. Alternatively, some women were derailed from their educational goals due to their partners' manipulative behavior.

Terry: Well, like I said I was a college dropout, and she offered to support me while I went back to college and got my degree and then encouraged me into... it wasn't a threat, but heavily encouraged me and kind of blackmailed me into applying for and then going to law school. It sounds really bizarre, but anyways. And well, she had the privilege out of this very fancy education and the status of her MD.

Betty: I was financially supporting her but, you know, that just sort of felt like more responsibility or something. I'm a mathematician and I think she, in retrospect, I think she probably had some learning disabilities. I mean it's just weird, I mean I remember this time that she went for a job interview to be an ambulance driver, which sort of seemed perfect for her because she always 
created crisis everywhere she went, but they had a math test and it was really a basic arithmetic thing and she failed it. I remember her coming home and screaming at me that it was because of people like me that people like her couldn't get jobs because I was good at math. I don't think she really had a job while we were together.

Robin: She would bring up, you know, how I'm not in school and I need to go back, which I agree with her I do need to go back, but she would do it to the point, you know, I didn't have the family. I guess what she did, I don't have anyone to help me, so you know, saving money was the biggest issue for me. Which I was trying to do, but it's hard to do that when you're paying the utilities, and the rent, and she didn't understand that.

A few women added non-traditional sources of power present in their relationships that they believe impacted the dynamics $(n=4)$.

Ellen: I had more privilege than her, but I didn't use it against her; there wasn't really a way. I don't think there was really a way that she had more privilege than me. Like I'm white and she's Chinese Canadian and she is kind of transgender looking whereas I when people look at me they think I'm straight.

Lauren: She also identified as kind of butch, and so, I know that was really, that was something that was really difficult for her. I guess one other way in which I had privilege that she didn't is that I did not, I'm not visibly queer looking. And she is visibly queer looking. I am fairly feminine, I always had long hair, I don't, you know, I don't have a lesbian haircut or whatever. She didn't either, but she always wore like men clothing, like men's cargo shorts, men shirts, like sports bras, you know had her hair like really in a tight ponytail back. She kind of looked more stereotypically lesbian than I did. Then there's also just the fact of where we came from. Like I grew up in Connecticut, you know a very liberal and accepting place, and she grew up in Alabama, which is not.

Dawn: She came from a much higher socioeconomic status. And we talked about "well, this is what I've done," and I was like "I'm sorry, I couldn't afford to do those things. Everything I have I worked for." I come from the bottom of the social economic status. College was an assumption for her. I disappointed people when I went to college because I'm a woman and I'm supposed to get married to a man.

Nadine: They [Nadine's abusive partners] were both Black and I am biracial, Black and Hispanic, so those really don't have any special privileges or social privileges I guess. But there were times when I would say we experienced like preferential treatment. I experienced that because like if I was wearing a hoodie and we were walking, people were more likely to like smile and look at 
me. But if she's wearing a hoodie and we're walking they're more likely to like shy away from her or like cross the street to avoid her and she would like feel really angry about that. I think there were a couple of times when she was like "maybe you should go ask because they're probably going to say yes to you."

Several participants indicated a power differential related to everyday choices and those decisions related to the household $(n=8)$. Participants reported feeling no control in this area or having no communication around issues that should have been considered jointly. As a result, participants and their partners made life choices separately without consideration to the relationship.

Ellen: No, no I felt like, no she just basically did whatever she wanted to do. She didn't show much consideration for my feelings about things that would be quite hard, just no.

Dawn: And that was the first time I've ever gone car shopping. For the last two cars or three cars that were purchased in the time that we were together. I was not a part of the decision making process. Like even after I wrecked the car and we purchased a new one she goes "it has to be safe for you." And I said ok, well this is what I want, this is what makes me feel safe and she said "nope, we're getting a jeep."

Nora: I decided to leave for a year when I applied to the [graduate] program in the first place...I think about my relationship now and I'm just like, first of all I would have never applied to be somewhere for a year [without my partner]. But it definitely would be like "we're moving together," you know? So yeah, we didn't make a lot of big decisions.

Irene: In the first relationship I don't think anyone would have looked at that relationship and said I had the power. I mean at best it was kind of a "fucked up consensual relationship" and at worst it was kind of, almost a pedophilia ring. So I mean I don't think there was really any power there.

Two women cited their appearance as providing them with power and privilege over their partners, which provided some ease in navigating society.

Terry: I was very physically attractive in the conventional sense at the time (laughs) and so I think I had that little bit of leverage, whatever, I don't know how it played out exactly, but it existed for sure. 


\section{Change in Abuse and Dynamics over Time}

The last research question investigated the extent that abuse/violence changed over time within their relationship or influenced the presence of abuse in subsequent relationships. For all participants $(n=12)$, abuse was seen as increasing over time and perpetrated only by their partners. One woman did acknowledge a single instance of physical violence towards her partner, which she described as situational as opposed to the more chronic abuse that characterized her partner's behavior.

Nadine: We were lying down and she was ignoring me and I felt already really angry and frustrated with her. She was angry and frustrated too, but she wasn't saying anything and so at one point I was just like yelling at her about why she wasn't answering me and why I was so mad at her. And the yelling... like I was yelling and crying and she still was just stone faced, not caring. And so then with my fist I started like hitting her. When she realized what I was doing, that's when she sat up and just like wrapped her arms around me so I couldn't move. But I would definitely call that abusive, because even though I was frustrated there's no excuse for me to like physically attack her.

Predictability of abuse. Half of the women reported that the abuse they experienced followed an unpredictable pattern $(n=6)$.

Karen: Totally unpredictable! She would be smiling one second and 10 seconds later she would be swinging something at me.

Sarah: Sometimes it would totally catch me off guard and I would think, "oh I should have realized that would happen," but you're just being a normal person. Well I would say "I'm being a normal person." We would be driving down the road and would look out the window and I wouldn't know what I was going to see there before I looked and there happened to be a man there and it just triggered it. So I got to the point that I would see a man and I would immediately have a reaction inside myself which is really bad, so, yeah.

Ellen: I would say more unpredictable. Yeah like she was she was usually, she was angry a lot but I couldn't predict like what things would make her angry

Nadine: With the first one (abusive relationship) I never knew really because she didn't really talk very much. I mean she talked but not about emotions really and so it was hard for me to predict with her. 
Three women shared that their partner's violent acts seemed more predictable and that their triggers could be identified, in order to avoid or prevent abuse. In Nadine's second same sex abusive relationship, she experienced what she believed to be a greater sense of what would lead to her partner's violent behavior, which she did not have with her first partner.

With the second one, I did know what would provoke her and I felt like I was walking on eggshells a lot of the time.

Irene recalled a predictable pattern of violence and calm, as seen in traditional models of male-perpetrated intimate partner violence.

Yeah I think it felt very predictable, right? It was you know, if I expressed displeasure, if I declined to do something, if I say no, this is what will happen. The first relationship followed like, a kind of traditional cycle of abuse where you see something that happens and then we have a honeymoon period and during those periods she would dote on me, she would buy me stuff. You know, she would kind of take care of me so to speak.

Robin expressed a similar sentiment to Irene within her own relationship.

Oh yeah I know, I mean I knew what made her mad. I made her, you know, feel stressed out. You know, so I would try to avoid talking to her about those things because I didn't want, you know, we lived in an apartment complex and the walls are thin and I didn't want anyone hearing our business, so I just avoided it altogether.

A third of the participants described experiencing both predicable and unpredictable patterns of violence, where certain aspects of their relationship could be traced to a future abusive act $(n=4)$. Other moments appeared to be erratic and volatile, keeping the women on guard at all times.

Terry: Yes and no, just like I said every whatever day it was I would be at my meetings, I knew it was going to happen. Things that were regular, for the regular blow ups, yes. And then there would be other things, we'd go out to eat and she would send the food back, and I would say "Why do you always have 
to send your food back?" and she'd get into a big fit, and we'd fight all the way home and so some was predictable, some wasn't. Something would set her off, set me off in terms of like "hey, you can't do that," "but of course I can" and I just knew that every encounter could well end in, not well, you know for me.

Dawn: Uh, definitely a little. Like certain things were predictable. Like, if I didn't have the laundry done by Sunday night at 9PM, there was going to be a problem. But other things, like I would just not tell her things or...I would avoid information or sharing things that would upset her, because I wasn't sure how upset she would get, if this would be the time she screamed at me or if she would just take any stride.

Lauren: Sometimes, like there were some things that I could predict, like when she wasn't good at something I could predict that she would kind of withdraw and like do her sort of, like, kind of self-dislike thing. But, there were definitely other times when I didn't really see it coming, when it was just like, she was just having a bad day for whatever reason, and I couldn't really predict it.

Next relationships. Following the resolution of their abusive relationships, the women in the study adopted different approaches towards dating life with future partners. Six women described a need to focus on themselves after ending their relationship. The period of solitude was used to manage subsequent chaos in their life, mental illness, or simply to facilitate self-reflection about their personal values.

Terry: I don't know, because that was a very long, long, long experience, and before that I had only dated or I only had one other steady girlfriend, so I wasn't well versed in what relationships were supposed to be like. And also, soon after meeting my next partner and moving in with her, I got diagnosed with bipolar. So things were in chaos a lot. And I had also quit my job and so I was scrambling for money and all this kind of stuff. But it was always all on, not the diagnoses, but the actual having bipolar and it also building, coming off of it. After leaving, just kind of triggering a psychotic episode or something, which I did have.

Dawn: Oh, I'm still considering considering dating. It's been 2 years. I don't say I'm considering dating, I'm considering actually considering dating. I...I'm terrified. Like, absolutely terrified. And having been through what I have, it can't be any worse. And that's a horrible way to look at it, but I think, I've never had problems with anxiety until I started my divorce. 
Nadine: So after being with her, I revised my list and came up with a whole new one. And I realized that she maybe fit half of the things on there, so that I've changed as far as like understanding more in depth what my values are and what I value in a partner. Not settling for just being in a relationship because I know that I did that in the past. And at this point in my life I'm not really willing to waste a whole lot of time just finding the right person. So if you don't meet like most of the criteria on my list, I'm not going to waste my time going on a date with you.

Nora: So I think I was at this point in my life where I was kind of like, "I don't want to date you; I don't want to date anybody."

Half the sample also prioritized committed relationships following their experience of intimate partner violence $(n=6)$. Some women pursued serious

partnerships immediately following the abuse. Gail shared that despite wanting purely sexual encounters and engaging in several brief relationships, she found that a new long term relationship renewed her faith in developing a healthy bond.

I started dating my current partner like a year and a half ago, so shortly after the other one. She's actually in my [graduate] program. So I don't know if that's a good thing or not, but we communicate really well and have a lot of the same interests, we're very respectful. I feel really comfortable talking to her about my emotions and very safe with my emotions and I didn't truly ever think that I would be. And so it feels very even and equal. Yeah, so there aren't all those expectations that you have to be a certain way or act a certain way.

Like Gail, Lauren shared her desire for casual relationships, but ultimately did not succeed in that pursuit.

I definitely didn't have, I've never been a one night stand type of person. And I actually am a little frustrated by that, because I really like the movement towards sexual freedom; I'm really about openness. But yeah, I mean when I got back from studying abroad, is when I was sort of opening myself up to the possibility of relationships again. I would've maybe considered something physical if I happened to find it, but I definitely preferred to find a relationship.

Ellen did explore her newfound sexual freedom, but ultimately found it unfulfilling. 
I only wanted to have a serious, I wanted to have a relationship but I think I got to the point where like I felt really, really down like and I didn't really know if it was going to be able to happen. And I did feel kind of like "fuck it" and I did do some like, probably risky sexual behavior for a little, but then I got into this relationship and I was really happy about it.

Nora remained willing to consider more serious relationships after a difficult period of dating multiple women with which she lacked a connection.

Yeah, you know I was open, I was kind of like, you know like I really, I had a relatively short period where I was like "oh I like girls and also let me try, this whole dating thing out." I was never not open to it, if that makes sense, to a more serious relationship.

Sarah, who was previously married to a man before her same sex abusive relationship, found this caused a great deal of jealousy for her partner. Though the two had met while Sarah was married, Sarah's past was a major source of conflict for her partner who constantly questioned her sexuality and commitment. Sarah described feeling a sense of security in her current relationship and decreased worry that looking at a man, particularly in a non-sexual way, will result in violence as it did with her prior partner.

So, my next partner I'm still with, is the woman I was working with on that team. So, that worked out but this has been a very wonderful and healing relationship. So, it's probably for the first, I don't know, 10 years or so it was just kind of like, healing, being in a normal relationship where, you know, having to get over reacting every time you see a man. I don't think about that anymore, thank goodness, but it took awhile for that reaction to go away. And, yeah it's been good. I feel like, since I've got out of that relationship and have had a period of time just to heal, I can now focus on my own career and put my energies into that and I'm now in grad school and I have the support of my partner to be in grad school. So I've, I finally feel like my life is taking off.

Others reported a heightened awareness towards new partners and the need to be especially careful not to fall victim to abuse again $(n=3)$.

Karen: I mean over time, it's kind of lesson learned. Somebody starts getting it, if someone starts having the crazy look in their eye, I run, I run. That's for sure. 
Betty: I went through this phase where I was in my early 20's and I was really kind of popular and had more self-esteem and having been this kind of nerdy kid and people thought I was cute and all that, so I think that I was more weary. I really only had, I mean I had one other relationship that... I really didn't get involved with people that much.

Robin not only had an increased concern for abuse, but also for infidelity given that she experienced it in her previous relationship. She shared her current worries related to her present partner.

Umm, yeah, she, the biggest thing is that she is going away to a big state university, which is about an hour and a half away. So I do have some anxiety about her cheating, but that's really it.

Two women described a desire to transition to less serious romantic commitments where the expectation of longevity was absent.

Terry: Yeah, I wanted something light and casual, very fun and romantic and sexual, and it was that for a while. Which was, you know, a relief.

Betty: I mean I had a couple flings. Yeah, I mean I did a little bit of that afterwards.

\section{Barriers to Help Seeking}

Eight of the women endorsed engagement in psychotherapy independently or with their abusive partner in an attempt to save the relationship. Regardless of therapy utilization, all women noted barriers during the help seeking process. Participants were asked what enabled them to leave their relationships and to describe the obstacles they experienced in doing so. Responses fell into two major areas - internal factors, or barriers they attributed to themselves, and external factors, or barriers caused by outside circumstances and individuals. 
Internal factors. Many women reported that their inability to recognize the abuse as violence was a major barrier to help seeking $(n=6)$. This was in part due to their lack of lesbian relationship models to reference in their own lives.

Terry: I guess first and foremost is even identifying to myself that I was being abused, and then being able to articulate it. Like "does this even happen to lesbians? Do women abuse women?" And then being able to articulate it to someone else, and then have them say, "oh this is really going on." So the barrier would be just my own intellectual barrier of "is this really happening?" number one, and "can this even happen between women?"

Gail: There's definitely not a template for "this is what maybe you should look out for" in terms of like domestic violence and stuff and in same sex relationships. Until you get into it you have no idea what you are doing and you think it's normal or you try to sort of just manage it the best way you can and then it gets out of hand and it's hard to go back.

Karen noted that even in her previous job as a domestic violence counselor, she was unable to distinguish abuse in her own partner's behavior.

And I had been for a number of years, I was the counselor, I did peer counseling and so on, and many times had dealt with folks who were in abusive relationships and it was different when it was me. Somehow I just got caught in the trap.

One third of women reported that nothing would have helped them leave their relationships sooner or seek out help, because of their distrust of others' opinions and inability to see the severity of the violence.

Sarah: That's a very good question. Um, I don't really know because I, I didn't talk to anybody about it. Uh, probably the barriers are my own, uh, pride or whatever.

Robin: It would've just had to be something that I would've had to realize later on, how bad this relationship was, because sometimes you just don't listen to people.

Karen: I would say I could do it myself. Yeah. And that's why when I see someone and I recognize, unless you can recognize what is happening, there isn't anything anyone can say or do. 
Alternatively, one fourth of women credited their own will and ability to selfreflect as strengths in regaining their lives back after the abuse. Karen described her turning point as a moment of clarity where she suddenly realized she needed to leave her partner.

It was, like you say it was like an "ah-ha moment." And it just like, suddenly all of a sudden I could see everything that had been happening and I was like "nope, this is the end, I'm done."

Nadine spoke of a conversation she had with a friend who facilitated a period of self reflection and allowed her to consider the consequences of continuing her second abusive relationship.

It was helpful to talk to her and then throughout the few weeks that passed after that, just like understanding myself more and having somebody who would just listen and be nonjudgmental, but at the same time be like "this is what you're getting if you decide to take her back."

Terry found that attending to the positive aspects of her life could help motivate her to overcome her circumstances and start life over again after her ten year abusive relationship.

I had things going on, a pretty hefty career so even though I was still depressed and still whatever, but I felt strong enough that I could leave. I just looked and thought "wow, this is exactly how I never wanted my life to be." And it's almost like, I'm married and with a child; it doesn't matter that the person I am "married" to is a woman, that's something I would never ever want in my life, and I was like I have to get out of this.

Another three women described making meaning out of the domestic violence they experienced as a healing mechanism. They included examples related to volunteer work and with their approach to their careers.

Betty: Oh and I did these child assault prevention workshops with the rape crisis center, that was helpful too. In retrospect, I don't know how effective 
that particular program was but it helped me. I don't know if it helped the children but, you know?

Sarah: I really feel like I want to, you know, make a difference for women who go through this and I feel like, I just feel like it's time for me to start talking about it so I have been. And, I mean there's always the worry that people are going to think poorly of you, you know, and maybe not respect your work as much or whatever but so far I've been getting good, good reception.

Ellen: When I do CBT (Cognitive Behavioral Therapy) with my clients, if they ever told me they were emotionally abused, I would be like "please tell me about that." I would be pumped about it!

Two women denied any barriers to help seeking and felt they did not require therapy to cope with the aftermath of their relationships.

External factors. A major external barrier for women seeking help related to therapist/service provider factors. Eight participants reported experiences of discrimination, insensitivity, and lack of knowledge from professionals they encountered. Both the fear and actual negative experience led to multiple iterations of therapy with different clinicians or avoidance of treatment altogether.

Terry: I also had my own therapist, or actually a series of therapists, all of them were lesbians actually at that time, and I had one who didn't help it. I had one therapist actually who said 'well what does she think?' And I said "What? Like she's the problem." She's (Terry's partner) a psychiatrist and she was secondguessing everything I said. Especially because I'm a social worker and my partner's a psychiatrist, so I was like "Oh my god, like, no one's listening to me here."

Karen: The attitude tends to be "well we can't have a lesbian come into a woman's shelter because she's going to go after all the women." That's the last thing you want to do, is get involved with another woman!

Robin shared her frustrations that no one believed she could have been abused because her partner was too feminine to perpetrate violence, therefore diminishing the participant's experience. 
Yeah because she was the more feminine one in the relationship so everyone thought that, like, "oh it's not that big of a deal. You'll be fine."

For some participants, like Betty, once engaged in therapy, there were interpersonal issues with the clinician preventing her from being assessed and treated appropriately.

She also acknowledged that in the 1980s when she experienced domestic violence, the cultural climate was different.

I mean you know it's funny, I was at graduate school and in order to get an outside therapist, because they only had psychiatrists at the time and all but one of them were men and there was no way I wanted to, you know? Well I remember the first time I got therapy, I had a guy asking me these questions like, you know, I remember at one point he asked me if I have any male friends and at the time I didn't but I lied and said I did because, you know, that was just a time when people were so afraid of getting locked up for being queer, you know? So, that was a little bit of a barrier but on the other hand it's nothing like the barriers people have now because once I got it, it was paid for; I just had to get a referral. I think that people didn't know what that was, you know, people weren't very good about domestic violence then.

Sarah shared a story of where medical staff failed to be concerned for her safety after her partner was hospitalized for chasing Sarah with a knife. Though Sarah's partner had admitted herself for homicidal behavior, Sarah was portrayed as the problematic party.

There was actually, when she went to the hospital, one thing that happened there that I wasn't very impressed with was that they were more concerned about her and me needing to leave the house and get out. And meanwhile, she went in and she readily admitted that she ran after me with a knife yet there was no concern about me and where I was going and what was happening. I found that very, very strange in the system and really not a good thing.

Nadine considered the racial dynamics present with potential therapists and their impact on her openness to treatment.

The first therapist I saw was white. The second one, she was black but I didn't continue seeing her and letting her know more about my experience because it was so expensive to go back. So if that barrier wasn't there then I do think she 
would have understood that, because even at the beginning when I was just telling her about my family dynamic she kind of was understanding like "okay if this is how it was with you and your mom." And you know she never said like "oh I've had the same experience," but just based on her reflections to me, I could tell like okay she actually gets it.

Two women cited financial barriers as preventing them from engaging or continuing in psychotherapy. Two women also reported their partners sabotaged efforts to utilize therapy, resulting in no treatment or attending only one session.

Nadine: So I didn't go [initially] but when we started having problems I went a couple of times and we had planned to go together, but there would always be some issue that came up where she couldn't come with me. So I wasn't as good at following through and staying in therapy. And also when I would come back and sometimes tell her okay this is a suggestion that the therapist has, she would get so defensive and just like, "what the hell does a therapist know about our relationship?" And "why were you even telling her all of that?" So that was I mean definitely wasn't a good thing.

Two additional women desired psychotherapy and believed it would have been helpful, but failed to attend due to a lack of family support.

Robin: A professional would've been helpful. Just to talk to, and see what to do. I mean, even a couples' counseling would've helped, but I mean my brother was there if I needed anything. But I pretty much did everything on my own.

Lauren: Well, yeah, my other best friend...I think if he had been closer at hand, I would've talked to him about it sooner. So I think that was part of it, you know, he was, he felt a little bit out of reach compared to how he had been in my life in the past. And so, but aside from that, the way my family was acting, I don't know, and the fact that my best friend was a little bit further away than I would've liked. Yeah, I don't really think there was anything anyone could have done to make me talk about it, or feel more safe talking about it sooner.

Despite the obstacles to help seeking, the majority of the women could identify support from friends, family, coworkers, and/or through treatment at some point after their abusive relationship $(n=9)$. 
Irene: Oh yeah, it was very, very helpful. I mean the therapist is very open and you know really just gave me a place to just talk and really bounce something off of someone and be like "this is the thing that happened." And to get someone like outside of the situation, and be like "you know that's not ok, right?"And she really started to put things together, what it was exactly that was happening and why it wasn't ok.

Gail: No actually my therapist was, actually pointed out some things to me, which was helpful. I felt like she was very helpful in that. Um, barriers. No, I mean even when I broke up with her, my friends were like "come over now, like right now" you know? And "you can move all your stuff in here until you find a place." And I didn't really, I can't think of any barriers once I started seeking help, I felt like I had the support that I needed.

Betty: I mean I had these two friends who had gone through the whole thing with me and they were tremendously helpful, and you know, they both, one of them actually worked at the shelter, she was an employee, and the other one was a volunteer. Also I had this job, well you know, I was out of money because I dropped out of school and I went to this temp agency, I got this job. It was supposed to be this typing job back when you typed on a typewriter, and then they found out I knew how to program computers and I managed to promote like, you know, you should really have this automated and I had this sympathetic boss; she had been battered herself and because I was getting paid like the crappy secretary rate she let me, she basically let me put down more hours than I actually worked as a way of sort of giving me a higher rate and so I had days when I was too depressed to go to work and she just sort of was ok with it.

Dawn: It was the day my counselor used the word of abuse. And I probably been seeing her for about 6 weeks and the first four months I couldn't get out of bed, much less do anything else. Because like, I literally went to work and came home and went to bed and that was how I functioned. And she goes, "I'm going to say it," she goes "because she was abusive." And I was like "no, she wasn't, but she never hit me." And then I heard myself say it. And my counselor really helped me get comfortable with that concept, as horrible of a concept as it is.

Lauren: So at the time I had been seeing someone already for some depression issues, and so it really just kind of rolled pretty naturally into

the conversation that I was already having with my therapist, you know, about the way that our relationship affected my mood, and kind of the way that I felt about how things were going between us, and my therapist and I would talk about you know my fears of you know her doing something drastic if I broken off, and we kind of talked about that.

\section{Advice Regarding Same Sex Partner Violence}


Over half the participants $(n=8)$ reported that if given the opportunity to inform others about same sex partner violence, they would want to stress that abuse can happen to LGBTQ identified people and should be validated when a woman discloses her experiences.

Karen: Abuse is abuse, regardless of who is doing it to whom. Robin: I would just tell them it's just the same as any other violence. It's no different. It can be just as cruel, just as emotionally abusive as any other relationship and it does happen.

Sarah: Just to be aware that it is there and it is possible for it to happen and that people may be even more reluctant to talk about it because it is same sex, you know, the relationship and there's, you know, stigma, unfortunately that still goes along with that so it's like a double stigma. So, just to make space for people to be able to talk I guess.

Gail and Irene noted that the impact of lesbian perpetrated abuse is trivialized compared to what society views as an abusive relationship in male perpetrated violence.

Gail: I guess just to see it as, as serious as a heterosexual couple. You know to, to see the same signs and same behaviors as equal to domestic violence on a straight couple, because I feel like it's often kind of swept under the rug or minimized. I mean that's definitely what I did even as a queer person.

Irene: I think we have this real societal view of women as caretakers so there's the thing like lesbians don't have DV (domestic violence) and it's just not true. And so when people kind of don't take it seriously or don't look closely enough at what's happening like when you have a heterosexual relationship, people can, if the male partner is an abuser, it's quite easy to spot...often because we look for that. And to just be aware that it's a thing and, and if you could switch the genders in your mind and it would be abuse, then it is abuse.

Another common response spoke to the need for professionals to have increased education around LGBTQ issues, and in particularly how they intersect with intimate partner violence $(\mathrm{n}=7)$. 
Irene: Just being, you know, more like more knowledgeable, more education for therapists around just being LGBT friendly.

Karen shared that often there is a perception that LGBTQ individuals are responsible for their own community problems. She urged for a more collective approach where everyone is invested in helping end same sex partner violence, regardless of sexual orientation.

It makes no sense to me, but that's the thinking. So, the more that we can educate the community, everyone. And it's not just, the gay community, the gay community it's not much better as far as that goes. "The two of them together, they can fight their own battles" eh not so much.

Lauren commented on specific power dynamic differences between same sex and opposite sex couples that professionals should be aware of, which would require a more in depth assessment of relationships patterns at the onset of treatment.

Well, what would I like them to know? I think I would like them to know that the power dynamics in a same sex couples are always categorically going to be different than those in an opposite sex couple because of kind of the structure of oppression and patriarchy present in our culture. So I think that in like female-female same sex domestic violence, that there is just a power aspect that is absent, and I think that can or cannot be filled in certain cases with a different type of power differential. So, like, I think it's more important with same sex couple to think about where the power differential is, rather than with opposite sex couples where you would at least know where it starts.

Similar to Lauren, Nora described the subtleties present in same sex abusive couples

that professionals or one's support group may not be looking for signs of violence.

I think what I would want them to know is that some of the classic sort of signs are not really there when someone is in a controlling relationship. And I think that you know, you think about it and you're like "yeah, I know I've heard isolation from all my friends, I've heard this. I know I heard like everything is in that person's name and you can't get away." But I think there are more subtle ways that it happens and I think that that would be something important to know. 
Nadine, who is a Black and Latinx biracial woman, spoke to education and increased

awareness around intersectionality for those women who identified with multiple

minority statuses that would likely compound stigma towards help seeking.

So I think I would share that there is a lot of stigma around first being in a same sex relationship and then navigating that space as a racial minority. Like, who's going to accept that I was abused [as a Black woman]? But who's also going to accept that I was abused by a relationship that they're not okay with? So there's I think twice the stigma. I mean, not just any race and the relationship, there are so many other levels of it. There's much more stigma I think when it comes to reaching out. So people should, you know, make it known that they are supportive of this person, that they love this person no matter what.

Participants also expressed the way they would like to be received by their support system and professionals when disclosing. Five women reported that exhibiting a direct approach and using interventions that were client-centered were most likely to facilitate disclosure of abuse. Ellen recalled a friend using a direct approach with her when trying to highlight the negative dynamics in a relationship before her abuse. She shared that a similar reflection from a friend may have helped her leave the violent relationship that occurred later.

Somebody told me, I was talking to him at bar, he was a friend of mine, and he was like "you sound like you have battered woman syndrome." The way that I was defending my girlfriend at the time after the things she had done that were like, not cool but not abusive. And that kind of snapped me out of it and that led to the end of that relationship. So maybe if somebody had said that to me about, about my next girlfriend the one that I've been talking about in this study, it might have helped snapped me out of it again.

Gail echoed Ellen's sentiments in her interview as she described an interaction with some of her friends who indirectly questioned her decreased presence.

Well I guess I don't blame them but yeah it I guess it would of made it more helpful if they had been more direct about what they were realizing because there were, there was one person who made a couple comments um but it was 
kind of like "oh you really don't get to see us very much anymore," you know? So I, looking back now I see that they were you now that one person was kind if trying to say it but didn't say it directly and that would have been helpful to hear that. I think because even if I would have been defensive about it, I would have thought about it, you know?

Terry described a long journey of searching for a therapist in light of mental illness and suicide risk.

Well, I found a therapist finally after three suicide attempts and three relationships later, who I saw for eight years, and she knew exactly what she was doing. And she asked the right questions, got to the bottom of all this stuff, we worked really hard together. So yeah I did finally find someone who listened to me and assisted me. But it took a while of going to a lot of really bad therapists and a lot of therapists who wouldn't even work with me.

Betty stressed the importance of having a therapist who helped create a sense of independence and autonomy in women recovering after an abusive relationship. Through her own journey with psychotherapy and founding a battered women's shelter for lesbians, she shared that agency is not emphasized in a world where people feel less control over managing their mental healthcare.

You know it's thinking that in there you have, you know there is some agency in there about how you want to be in the world. I mean I would imagine that as a clinician that it's all completely different now, because there's all the drugs and the time limit and you know I don't know. But I think, it was very complicated.

Lastly, four women indicated that fostering a sense of connectedness with survivors by showing kindness and support can imbue a sense of hope. Participants stated that they tended to isolate both during and after their abusive relationships, which could have been penetrated by explicit demonstrations of support and safety.

Sarah: Um, I don't know I think maybe demonstrating kindness for somebody and caring might give somebody, you know, the thought that what they are experiencing isn't ok. I don't know, I don't know, that's a hard one, that's a 
really hard one. I think when you don't value yourself it's really hard to take it in and to do something different for yourself and that's a long process.

Irene: You know if I had some more insistent friends that were kind of calling me and talking to me rather than just letting me isolate; that would have been helpful. I guess following up, right? Because people want to isolate and not letting them go there, knowing like giving a support system when they aren't trying to get support, it would be really helpful.

Betty reflected on her relationship with her current partner and how surprisingly, her partner's 21 year old daughter aspires to have relationship like theirs. Her response suggests that women often feel it is impossible to have a healthy romantic relationship after abuse, but that being given that advice may have made an impact.

We're like their role models. I was saying that, that is the most shocking thing that I think has ever happened in my life that these 20 year olds would think that just by watching my relationship that it would be a role model for what they want in their life. So, you know, so I think that kind of hope is important. I mean not that I would've believed you at the time but you know? I said ok that's true for those other people, not for me.

\section{Questions for the Researcher}

Each participant was given the opportunity to ask questions at the end of each of their interviews. Half of the participants had follow-up questions related to analysis of the data and the methodology involved in the project $(n=5)$. Other questions included: research questions informing the study $(n=1)$, when the study would be finished $(n=1)$, personal background of the researcher $(n=1)$, and inquiry about whether the participant's story was consistent with other women's reports $(n=1)$.

\section{Follow-up Interview Reflections}

Though all twelve participants consented to setting up follow-up telephone calls, only a portion of participants agreed to speak after the initial interview $(n=8)$. All participants denied distress post interview as a result of their participation in the 
study. Five women had no questions related to the study, while 3 had questions about the methodology of the study. Such questions related to using quantitative versus qualitative methods, understanding the research questions that informed the interview guide, and concerns about how specific identifying information would be kept anonymous.

Each participant was also asked to consider what they would tell a friend who had experienced same sex partner violence about their participation in the study and if they would recommend it to others. All women said they did and/or would recommend a friend to a similar study and provided their advice for women considering sharing their story in a research study. Generally women expressed their gratitude for being allowed a space to discuss their stories openly and felt their participation represented a positive effort to educate about same sex partner violence.

Betty: I think that it is important to tell these stories to someone who will listen. Which is, I think what you're trying to facilitate on a wider scale and then on a smaller scale - that's what you're doing.

Nadine: I definitely would recommend it to others because I don't feel like we are often given the space and the time to sit and talk about these experiences, especially in so much depth, so I would say... like in a way it was kind of liberating to talk about some of these things so I would definitely recommend it.

Lauren: It was actually really fun to talk about it. And I know that's a little weird, but I feel like so much distance from it, but it was just nice to kind of talk about it and help you with your project. It felt good to feel like I really moved on from that phase of my life - it was a long time ago.

Women also reflected on how their participation in the study allowed them to see how much they had overcome after their abusive relationships, or what they still needed to process. 
Nadine: I realized, like I was talking to you the last time we spoke, that I did feel like a little bit emotional and I hadn't talked about some of those things so far. But it was really good for me because, afterwards I was able to like write about my feelings and just process stuff that I guess had been unprocessed.

Gail: I had done some work around it for a while and then it had been a while since I really looked at it and so it was definitely easier for me to talk about it now which was nice for me to see. And it was good to go back in terms of just seeing the progress that I have made since then, in my relationships. I don't know, it was mostly just very reflective, self reflective...it's just, it was good I would definitely recommend it, cause I think it's research that really needs to be done.

Two women advised others to make sure they had someone else in their life to talk to about these issues before agreeing to participate, so that they could process with a trusted individual after the interview ended. Dawn spoke specifically about how she was surprised at other incidents she remembered from her relationship as a result of her participation.

I've always been pretty comfortable talking about some things but there are other things like talking about the movies I stopped watching, it's a little embarrassing that I let somebody do that. But I don't know, it's definitely getting easier. 


\section{CHAPTER 5}

\section{CONCLUSION}

As research regarding women's same sex partner violence remains limited, this study aimed to qualitatively explore the way women describe their experience of power and control with a same sex abusive partner. The interviews yielded rich descriptions of the types of abuse experienced, areas of control they endured, and insightful reflections on how to promote help seeking around these issues.

\section{Types of Abuse}

The women in the study described a wide range of abusive acts that transpired in the context of their past relationships. Notably, all participants reported abuse happening early on in their relationships and/or at the onset of cohabitation. Several women $(n=8)$ identified the abuse as occurring with their first same sex partner, which is consistent with prior research that found a similar pattern in a sample of LGB abuse survivors (Ristock, 2003). All twelve women also endorsed psychological abuse and manipulation, including name calling and criticism. Physical abuse and threats were also quite prevalent, with women citing being slapped, pushed, grabbed, and enduring threats of serious bodily injury or death $(n=10)$. Less common, but equally traumatic were reports of threatening behavior towards participants' loved ones, their partners threatening to kill or harm themselves $(n=4)$, and sexual violence $(n=3)$. Not

surprisingly, the scope of violent acts perpetrated against same sex intimate partners is 
varied and encompassed behaviors that violate women emotionally, physically, and sexually (NCAVP, 2014).

\section{Power and Control}

A number of areas where participants felt they lacked power, control, and influence emerged from the data. Most commonly women believed they were disempowered by their inability to discuss or negotiate relationship concerns with their partners $(\mathrm{n}=10)$. Attempts to discuss their own distress were met with aggression or were ignored to the point where women stated it was no longer worth it to talk about what bothered them. Alternatively, when their partners' expressed concerns, there was an assumption that the women would automatically acquiesce. Limiting of social activities and networks was another common power dynamic for women $(n=10)$. The isolation from family and friends, as well as the placement of guilt on participants for not abandoning meaningful parts of their lives resulted in feelings of resentment on the part of the women. Interestingly, women described a mix of experiences related to financial control in their relationships $(n=9)$, such that both being the primary wage earner for the household or not could still lead to victimization. Participants reported typical patterns of financial dependence on their partners, which restricted their ability to meaningfully carry out necessary tasks or to arrange to leave the relationship. On the other hand, multiple women indicated that despite being the breadwinner, they were manipulated into taking care of partners who refused to maintain employment or enrollment in school. Often participants were using their money to finance their partner's alcohol or substance use to prevent additional violence or tension from emerging. 
Similarly sexual power $(\mathrm{n}=8)$ and influence related to one's sexual orientation or gender identity $(n=9)$ exhibited polarizing patterns in the sample. Both one's own sense of confidence and comfort with sex, gender expression, and sexual orientation could be seen as problematic, as well as that of the women's partners. Regardless of how the women identified, many experienced constant harassment around returning back to romantic relationships with men, threats of being outed to one's family, or not being an authentic enough lesbian, if they had no disclosed their sexual orientation or were not engaging in sex enough for their partner. Internalized shame and lack of selfconfidence on the part of the women's partners also appeared to be a tool to manipulate the participants into feeling guilty or inadequate, despite not necessarily having any identity issues of their own.

Additionally educational control was present for many women $(n=7)$ who cited criticism from their partners for not achieving more academically, being accused of thinking they were better than their partners for the education they had obtained, or being prevented from working towards higher levels of education. Like education, other miscellaneous or non-traditional sources of power were areas where women had the potential to have some influence over their partners. Such areas included race/ethnicity, gender expression, and family of origin support. In the domains where participants cited having some privilege, it did not appear to impact the experience of abuse. Though not outweighing the costs, these seemingly small advantages created some room for women to benefit from negative and toxic situations, if only in a minimal way. For example, Terry who described being manipulated into pursuing an unwanted law degree, noted that she in some ways benefitted from having someone 
take care of her living and educational expenses while completing her studies. Law school also provided her with an outlet away from her abusive partner with coursework. In exchange, she was able to say she has earned her degree in light of significant obstacles co-occurring at the time of her studies.

The power imbalances that women described in the study reinforce previous research that found when there are greater demands for obedience from the abusive partner, power imbalance, and inequality when making decisions related to sex, the relationship, and social behaviors, SSDV increases (Eaton et al., 2008; Stevens, Korchmaros, \& Miller, 2010; West, 2002). There may also be increased struggles to negotiate power and one's role in a same sex relationship when it is a woman's first time with a same sex partner. The majority of this sample indicated they experienced SSDV in their first ever or first serious relationship, therefore navigating what it means to be in a romantic partnership with another woman, without templates or healthy references could leave women vulnerable to IPV (Ristock, 2003).

\section{Changes and Patterns of Abuse}

Results involving the pattern of abuse within the sample's abusive relationships was mixed. Women indicated they generally experienced violence as unpredictable $(n=6)$, and to a lesser degree violence was perceived as predictable $(n=3)$ or a mix of the two $(n=4)$. Women often described scenarios where they were in a constant state of anxiety in an attempt to manage their environment. In a sense, erratic chaos was the common element. Overall, the entire sample described abuse as one-sided in all relationships, with a few exceptions of situational violence or selfdefense among the women. Abuse also tended to increase in terms of severity, 
intensity, and frequency for the participants. Though findings were also mixed with regard to women's dating behavior after the violence, with most opting for serious relationships $(n=6)$ or pursing a period of self-reflection $(n=6)$, as opposed to casual dating $(n=2)$. None of the women reported becoming perpetrators in any of their subsequent relationships. The current study showed some evidence consistent with prior research findings that women in same sex abusive relationships often endure predictable cycles of violence where there is a clear perpetrator and victim between periods of calm (Ristock, 2003). Nadine, one of the participants who had experienced IPV with two men and two women, noted that in her experience men tended to exercise more severe physical and sexual abuse than the women who perpetrated violence against her. Emotional manipulation in her opinion, was similar, though easier to identify. Nadine's perspective was not unique - for half of the participants, identifying their relationships as abusive was a major obstacle and impacted their propensity towards help seeking.

\section{Help Seeking and Recommendations}

Based on participant feedback and advice, there are a number of recommendations that can inform and improve therapists' interventions. Given half of the women endorsed a poor recognition of violence in their relationships due to lack of models and two-thirds reported negative interactions with professionals, it is important for those in helping professions to manage their attitudes and biases. First and foremost, women highlighted the significance of acknowledging the presence and seriousness of same sex partner violence. Comments that minimize, trivialize, or distort abuse, especially when one-sided, can result in damaging consequences for 
women. As seen in this sample, LGBT women already experience sufficient personal barriers with underrating and denying the existence of SSDV, leading to the perpetuation of silence among victims (Balsam, 2002). Additionally, an inability to properly assess the scope of IPV within same sex relationships can be equally harmful. It is not uncommon for service providers to feel overwhelmed by the complex nature of lesbian relationships and miss important context during an assessment (Ristock, 2003). Moreover, rigid adherence to models of male-perpetrated violence and gender role stereotypes often prove to be unhelpful because those patterns do not always translate to women's same sex couples when traditional indicators of abuse are not present (Ristock, 2003; Seelau \& Seelau, 2005). This inflexible thinking towards the context of same sex partner violence, in addition to intolerant attitudes from one's support systems or therapists facilitates challenges women face when engaging with other social institutions as well. In line with participants' reports, women often experience re-victimization, shame, and hopelessness when entities meant to help them, such as police, shelters, or attorneys, are homophobic and discriminatory (Hardesty, Oswald, Khaw, \& Fonseca, 2011; McClennen, 2005; Oswald, Fonseca, \& Hardesty, 2010; Poorman, 2001).

As was suggested by participants, specialized education regarding LGBT issues and identities is crucial to serving a vulnerable population stigmatized by at minimum sexual orientation and their experience of SSDV. Professionals need education to assist in changing policies, establishing programs, and providing appropriate screening/intervention strategies that are cultural sensitive to same sex couples (McClennen, 2005). In addition to education, it is important to seek 
supervision or consultation to obtain a greater understanding of dynamics present in women's same sex relationships, as well as homophobia and discrimination against sexual minorities (Hamberger \& Phelan, 2006; Oswald, Fonseca, \& Hardesty, 2010; West, 2002). It is valuable to collaborate with LGBT agencies to serve as referral sources and consultants, then following up with clients to solicit feedback to assess whether their needs were met after resources given (Helfrich \& Simpson, 2006).

Participants also stressed the importance of basic factors to facilitate a trusting environment for women who disclose SSDV. Kindness, warmth, empathy, and collaboration were all cited by women as vital in their healing process. They described this as particularly useful when they felt no amount of intervention could have allowed them to leave their abusive partners before they were ready. Other essential components to recall throughout the process include being supportive, nonjudgmental, and validating while asking questions (Singh, Petersen, \& Singh, 2014).Using some sort of short screening measure can be beneficial, along with some sort of intervention to follow up (e.g. safety planning, referral for support services, treatment of health conditions, and mandatory reporting if required) reflect minimal standards to use when assessing for IPV (Singh, Petersen, \& Singh, 2014).

\section{Limitations}

Women, especially sexual minority women, are often underrepresented in research and their -perspective is frequently overlooked. Though this research seeks to add to the literature about the types of abuse and power dynamics that contribute to same sex domestic violence, generalizing these findings with different subgroups will add legitimacy to queer women. Nevertheless there are several drawbacks to the study 
that may compromise the generalizability to other women who experience same sex partner violence.

This study embraced women who do not identify as lesbian, gay, or bisexual to account for women in different stages in the coming out process, and also women who self identify in several different ways. Though participants were invited to participate regardless of sexual orientation, identification with a particular label or an experience as someone who engages in same sex relationships may impact individuals' comfort with participating. The way an individual makes sense of their own sexual orientation or the degree to which an individual experiences internalized homophobia, could decrease their likelihood of participating. In a related example, a potential participant presented a question during the recruitment process asking if transgender women were eligible, which speaks to concerns about gender identity and expression, resulting in dissonance preventing study participation.

Great efforts were made to be inclusive of all races and ethnicities, so as to reflect the additional minority stress experienced by women with more than one stigmatized identity. The current set of participants represented some diversity in terms of racial/ethnic identity, gender identity, and geographic location, but by no means characterize the total experience of all women who experience same sex partner violence. In general, the present study was primarily white, well-educated, and had at some point engaged in therapy related to their abusive relationships and/or other prior life stressors (e.g. childhood abuse, pre-existing mental health condition).

Similarly, participation requires the acknowledgement and insight into one's experience of intimate partner violence. As seen in the current study, several women 
went through their own journey to identify their relationships as abusive. This idea is consistent with prior research citing the challenges with recruiting sexual minorities due to their level of outness and stigma experienced for identifying oneself as LGBTQ (Meyer \& Wilson, 2009). Additionally a number of participants $(\mathrm{n}=7)$ disclosed their background in psychology and/or providing psychotherapy, which may represent a bias in the individuals who self-selected themselves for the study. Those individuals may also differ in the degree of self-reflection post-abuse and intensity of emotional distress related to abuse they experienced. Also access to the study was limited to individuals who have some degree of computer literacy and internet access in order to complete online screening and schedule phone interview via email. A certain population of eligible women were likely eliminated as a result of this. Phone interviews also pose a concern in terms of being able to respond to the physical indicators of the participant throughout the interview. Though phone interviews can provide a greater sense of comfort and anonymity while still providing a space to share one's story, the interviewer is not able to discern the meaning of certain indicators, such as silence or facial expression. Finally, information obtained from study participants was constrained by their memory of events, that for some occurred several decades ago, thus inaccuracies in recall and interpretation are likely. Similarly, for many of the women, there was a significant amount of time since their abuse occurred and the social context at the time of their violence relationships could have been notably different, therefore impacting their perception of barriers to help seeking or leaving their partners.

\section{Future Directions}


Based on the current study's findings and limitations, several recommendations are made to further improve on the current body of knowledge. For the future, researchers should continue to make special efforts to reach out to racial and ethnic minority groups, as well as a range of educational and socio-economic backgrounds to increase generalizability to women who experience same sex partner violence. Furthermore, conducting this study comparing women of different gender and sexual identities on power and control concepts would also result in noteworthy findings that need attention in this research area. It is also important to make distinctions apart from gay and heterosexual male-perpetrated violence, which manifests itself in more physically aggressive ways than female violence. Attempts to combine all LGBTQ individuals blindly can lead to an interpretation of results that overestimate the way we understand the psychosocial factors contributing to IPV for each group.

In addition to considerations to demographic factors, pre-existing mental health issues, suicidal ideation/self-harm behaviors, alcohol and substance use, prior traumas, and family of origin appeared to influence women's ability to make objective decisions about their relationships in this study. In general, predictors of women's same sex violence include presence of violence in the family of origin, substance abuse, relationship dependency and fusion, low socioeconomic status, and alcohol/substance use (Seedat et al., 2005; West, 2002; West, 2012). These findings were also replicated in a sample of Black lesbians, in addition to childhood sexual abuse, mental health symptoms, and multiple and intersecting form of oppression (e.g. race, gender, and sexual orientation intersection) (Hill, Woodson, Ferguson, \& Parks, 
2012). Though not formally assessed, the aforementioned factors emerged repeatedly in interviews as possible contributing factors to the abuse women experienced. They also described these factors as further obstacles preventing them from seeking help or leaving their partners. Future research should consider a direct investigation on the presence of these factors in women's SSDV and how women make sense of those experiences.

As it relates to therapeutic work, educational initiatives are needed to give clinicians, teachers, and domestic violence workers the tools to appropriately confront sensitive issues related to LGBT identities. Several participants reported that facing the double stigma of disclosing IPV in the context of a same sex relationship was a barrier to help seeking. Professionals employed to provide therapeutic services and direct safety planning do a disservice to women who have the courage to leave difficult and often dangerous situations for a healthier life. It is encouraged that on an individual and systems level, efforts are made to increase cultural competence to execute more ethical, sensitive work.

\section{Conclusion}

This study was conducted in order to gain a better understanding of women's description of abuse and power dynamics in same sex relationships. The findings supported much of the previous research and produced new trends that will be beneficial to the field of SSDV. Continued research to understand same sex domestic violence, appropriate treatment considerations, and education on how intimate partner violence manifests in this population will be greatly important moving forward. 


\section{TABLES}

Table 1

Demographic information about study participants

\begin{tabular}{|c|c|c|c|c|c|}
\hline Participant & Age & Sex & Gender & $\begin{array}{c}\text { Sexual } \\
\text { Orientation }\end{array}$ & $\begin{array}{l}\text { Relationship } \\
\text { Status }\end{array}$ \\
\hline Karen & 71 & Female & $\begin{array}{c}\text { No-op } \\
\text { Transsexual }\end{array}$ & Lesbian & Single \\
\hline Terry & 52 & Female & Female & Lesbian & Relationship \\
\hline Lauren & 29 & Female & Woman & Bisexual & Single \\
\hline Dawn & 33 & Female & Female & Lesbian & Divorced \\
\hline Robin & 20 & Female & Female & Lesbian & Relationship \\
\hline Sarah & 53 & Female & Female & Lesbian & Married \\
\hline Ellen & 31 & Female & Female & Bisexual & Relationship \\
\hline Irene & 26 & Female & Female & Lesbian & Relationship \\
\hline Gail & 27 & Female & Gender Fluid & Gay & Relationship \\
\hline Nadine & 26 & Female & Woman & Lesbian & Single \\
\hline Nora & 31 & Female & Woman & Lesbian & Married \\
\hline Betty & 53 & Female & $\begin{array}{c}\text { Female/Gender } \\
\text { Non- } \\
\text { Conforming }\end{array}$ & Lesbian & Relationship \\
\hline
\end{tabular}


Table 2

Demographic information about study participants continued

\begin{tabular}{|c|c|c|c|c|c|c|c|}
\hline Participant & Edu & Employ & Race & $\begin{array}{l}\text { Latinx } \\
\text { Ethnic }\end{array}$ & Therapy & $\begin{array}{l}\text { PCL } \\
\text { Score }\end{array}$ & $\begin{array}{c}\text { BDI- } \\
\text { II }\end{array}$ \\
\hline Karen & $\begin{array}{l}\text { High } \\
\text { School }\end{array}$ & Retired & White & No & No & 17 & 0 \\
\hline Terry & Graduate & Part Time & White & No & Couples & 21 & 1 \\
\hline Lauren & Graduate & Full Time & White & No & Individual & 20 & 7 \\
\hline Dawn & College & Full Time & White & No & Couples & 21 & 2 \\
\hline Robin & $\begin{array}{l}\text { High } \\
\text { School }\end{array}$ & Full Time & $\begin{array}{l}\text { White; } \\
\text { American } \\
\text { Indian }\end{array}$ & Yes & No & 29 & 16 \\
\hline Sarah & College & Part Time & White & No & Individual & 29 & 2 \\
\hline Ellen & Graduate & $\begin{array}{l}\text { Unemployed, } \\
\text { Not Looking }\end{array}$ & White & No & No & 33 & 15 \\
\hline Irene & Graduate & Part Time & White & No & Couples & 25 & 6 \\
\hline Gail & Graduate & Full Time & $\begin{array}{l}\text { White; } \\
\text { American } \\
\text { Indian }\end{array}$ & No & Individual & 30 & 6 \\
\hline Nadine & Graduate & Part Time & Black & Yes & Individual & 22 & 2 \\
\hline Nora & Graduate & Full Time & Black & No & No & 22 & 5 \\
\hline Betty & Graduate & Full Time & White & No & Individual & 21 & 2 \\
\hline
\end{tabular}

Edu - Highest level of education

Employ - Current employment status 


\title{
APPENDICES
}

\author{
Appendix A \\ Recruitment Advertisement
}

Dear [Name of Listserv/Name of Organization],

My name is April Trotman and I am a doctoral student at the University of Rhode Island studying clinical psychology. I am seeking participants for my dissertation study on relationship and power dynamics of women who have experienced domestic violence in a past same sex relationship. Domestic violence includes verbal, emotional, physical, and sexual acts that either partner uses to hurt, control, and/ or manipulate the other. This purpose of this research is to understand the forms and patterns of abuse in the LGBTQ community and to inform the assessment and treatment of women's same sex abusive couples. Participation includes a brief online screen and introduction to the study and a 4560 minute phone interview if they are determined to be eligible. Note that women's sexual orientation is flexible and they can identify however they choose, as long as they would not identify the past relationship as heterosexual.

Identifying information will be kept confidential.

Interested individuals are eligible if they:

- self identify as a woman

- have experienced domestic violence with a past same sex partner, as

defined above (inflicted on partner, received by partner, or both)

- are NOT currently in a relationship where domestic violence or abuse of any kind is present

- do NOT exhibit current distress levels during the online screen that may inhibit study participation

To learn more about the study, follow the link: https://www. surveymonkey.com/r/F6GVQFH

Please share this announcement with any individuals that may be interested in or eligible for this study.

Thank you for your interest in this important topic!

This study has been approved by the University of Rhode I sland Institutional Review Board (Approval Number: HU1516-109). Please contact the study investigators with questions: April Trotman (april.trotman@gmail.com) or Patricia Morokoff, PhD at (morokoff@uri.edu). 
Appendix B

Informed Consent

The University of Rhode Island

Department of Psychology

10 Chafee Road, Kingston, RI 02881

Title of Project: Relationship and Power Dynamics in Women's Same Sex Abusive Couples

\section{CONSENT FORM FOR RESEARCH}

Dear Participant,

You have been invited to take part in a research project investigating relationship dynamics in women's same sex couples where partner violence was present. This form explains the project to you in detail. Please feel free to ask any questions. If you have more questions later, you may contact April Trotman (919-454-1679), Patricia Morokoff, PhD (401-874-2685), or Ginette Ferszt, PhD (401-874-5345) to discuss them with you. You must be at least 18 years old to be in this research project.

Description of the project:

This study examines the specific relationship dynamics present in women's same sex relationships where partner violence was present. You will be asked to describe the forms of abuse and violence you experienced, as well as the ways in which you believe control may have influenced the dynamics of the relationship. Your participation in this study will help to inform research on how to help women seeking services and counseling for domestic violence.

What will be done:

If you decide to take part in this study, you will be asked demographic questions, questions about distress you may be currently experiencing and about your past relationship with another woman where there was some form of abuse or violence. You will also have the opportunity to provide feedback about what important information you feel helping professionals should know about same sex partner violence. Initial questions will be answered on an internet survey and if you are eligible, you will set up an interview time via email. The interview will occur over the phone at your convenience, in a safe location. The initial survey should take about 20 minutes or less. The interview questions will last no longer than 60-90 minutes.

Risks or discomfort:

Participation in this study could cause discomfort or distress, as you will be asked to reflect back on a time in your life where there was violence or abuse in a previous romantic relationship.

Benefits of this study: 
Although there will be no direct benefit to you for taking part in this study, the researcher may learn more about the relationship dynamics and experiences that occur in women's same sex partner violence. Findings from the study will also be used to benefit other women struggling with domestic violence. Some women who participate in research about past difficult experiences, find interviews therapeutic and help them gain insight about their own lives.

\section{Confidentiality:}

Your participation in this study is confidential. None of the information will identify you by name. All scheduling correspondence will occur through a secure email account designated for study communication. Phone interview files and study records will be stored in a locked file cabinet at the University of Rhode Island in the Department of Psychology for three years, after which time they will be destroyed.

Decision to quit at any time:

The decision to take part in this study is completely voluntary. You do not have to participate. If you decide to take part in the study, you may quit at any time.

Whatever you decide will in no way penalize you.

Rights and Complaints:

If you are not satisfied with the way this study is performed, you may discuss your complaints with April Trotman (919-454-1679), Patricia Morokoff, PhD (401-8742685), or Ginette Ferszt, PhD (401-874-5345), anonymously, if you choose. In addition, if you have questions about your rights as a research participant, you may contact the office of the Vice President for Research and Economic Development, 70 Lower College Road, Suite 2, University of Rhode Island, Kingston, Rhode Island, telephone: (401) 874-4328.

You have read the Consent Form. Your questions have been answered. Your signature on this form means that you understand the information and you agree to participate in this study.

Signature of Participant

Typed/printed Name
Signature of Researcher

Typed/printed name

Date

Date

Please sign both consent forms, keeping one for yourself 
Appendix C

Demographic Measure

Please complete the following questions related to your identities and general characteristics.

1. What is your current age?

2. What was your assigned sex at birth?
a. female
b. male
c. intersex

3 . What is your gender identity?

4. How would you describe your sexual orientation?
a. heterosexual or straight
b. gay
c. lesbian
d. bisexual
e. something else not listed/I'm not sure

5 . What is your current relationship status?
a. single
b. in a relationship
c. married/civil union/domestic partnership
d. divorced/separated
e. widowed

6. What is the highest level of education you have completed?
a. 8th grade or less
b. some high school
c. high school diploma/GED
d. college degree (e.g. Bachelor's degree)
e. graduate degree and/or professional degree (e.g. MA, PhD, MD)

7. What is your employment status?
a. employed, full time
b. employed, part time
c. not employed, looking for work
d. not employed, not looking for work
e. retired
f. not able to work due to disability

8. What is your race? (select all that apply)

a. White/Caucasian/European American

b. American Indian/Alaska Native

c. Asian (Asian Indian, Chinese, Filipino, Japanese, Korean, Vietnamese, Other)

d. Pacific Islander (Native Hawaiian, Guamanian, Samoan, Other Pacific Islander)

e. Black/African American

f. Other 
9. Are you of Hispanic, Latina, or Spanish origin?
a. no
b. yes

10. Have you ever sought out counseling/therapy or other services for relationshiprelated concerns?
a. no
b. yes, independently
c. yes, with my partner

11. Would you identify yourself as someone who has been in a past relationship with a same sex partner where domestic violence occurred? Domestic violence includes verbal, emotional, physical, and sexual acts that either partner uses to hurt, control, and/or manipulate the other.
a. no
b. yes

12. What is your preferred email address? (this will be used to schedule the phone interview) 


\section{Appendix D \\ PTSD Checklist - Civilian Version (PCL-C) \\ (Weathers, Litz, Herman, Huska, \& Keane, 1993)}

Below is a list of problems and complaints that people sometimes have in response to stressful life experiences. Please read each one carefully and in the space provided, indicate how much you have been bothered by that problem in the last month.

1 = "not at all", 2 = "a little bit", 3 = "moderately", 4 = "quite a bit", 5 = "extremely"

1. Repeated, disturbing memories, thoughts, or images of a stressful experience

from the past?

2. Repeated, disturbing dreams of a stressful experience from the past?

3. Suddenly acting or feeling as if a stressful experience were happening again (as if you were reliving it)?

4. Feeling very upset when something reminded you of a stressful experience from the past?

5. Having physical reactions (e.g. heart pounding, trouble breathing, or sweating) when something reminded you of a stressful experience from the past?

6. Avoid thinking about or talking about a stressful experience from the past or avoid having feelings related to it?

7. Avoid activities or situations because they remind you of a stressful experience from the past?

8. Trouble remembering important parts of a stressful experience from the past?

9. Loss of interest in things that you used to enjoy?

10. Feeling distant or cut off from other people?

11. Feeling emotionally numb or being unable to have loving feelings for those close to you?

12. Feeling as if your future will be cut short? 
13. Trouble falling or staying asleep?

14. Feeling irritable or having angry outbursts?

15. Having difficulty concentrating?

16. Being "super alert" or watchful or on guard?

17. Feeling jumpy or easily startled? 


\section{Appendix E \\ Beck Depression Inventory -II (BDI-II) \\ (Beck, Steer, \& Brown, 1996)}

This questionnaire consists of 21 groups of statements. Please read each group of statements carefully and then pick out the one statement in each group that best describes the way you have been feeling during the past two weeks, including today. Select the number beside the statement you have picked. If several statements in the group seem to apply equally well, select the highest number for that group. Be sure that you do not choose more than one statement for any group, including item 16 (changes in sleeping pattern) or item 18 (changes in appetite).

1. Sadness

O I do notfeel sad.

$1 \quad$ Ifeel sad much of the time.

$2 \quad$ I am sad all the time.

3 I am so sad or unhappy that I can't stand it.

2. Pessimism

O I am not discouraged about my future.

1 Ifeel more discouraged about my future than I used to be.

2 I do not expect things to work out for me.

$3 \quad$ Ifeel my future is hopeless and will only get worse.

3. Past failure

o I do not feel like a failure.

$1 \quad$ I have failed more than I should have.

$2 \quad$ As I look back, I see a lot of failures.

3 I feel I am a total failure as a person.

4. Loss of pleasure

O I get as much pleasure as I ever did from the things I enjoy.

$1 \quad$ I don't enjoy things as much as I used to.

2 I get very little pleasure from the things I used to enjoy.

3 I can't get any pleasure from the things I used to enjoy.

5. Guilty feelings

o I don't feel particularly guilty.

1 I feel guilty over many things I have done or should have done.

2 Ifeel quite guilty most of the time.

$3 \quad$ Ifeel guilty all of the time.

6. Punishment feelings

o I Ion't feel I am being punished.

$1 \quad$ Ifeel I may be punished.

$2 \quad$ I expect to be punished.

3 I feel like I am being punished. 
7. Self-dislike

$0 \quad$ Ifeel the same about myself as ever.

$1 \quad$ I have lost confidence in myself.

$2 \quad$ I am disappointed in myself.

$3 \quad$ I dislike myself.

8. Self-criticalness

o I don't criticize or blame myself more than usual.

1 I am more critical of myself than I used to be.

$2 \quad$ I criticize myself for all of my faults.

3 I blame myself for everything bad that happens.

9. Suicidal thoughts or wishes

o I don't have any thoughts of killing myself.

$1 \quad$ I have thoughts of killing myself, but would not carry them out.

$2 \quad$ I would like to kill myself.

$3 \quad$ I would kill myself if I had the chance.

10. Crying

O I don't cry any more than I used to.

$1 \quad$ I cry more than I used to.

2 I cry over every little thing.

3 Ifeel like crying, but I can't.

11. Agitation

o I am no more restless or wound up than usual.

$1 \quad$ Ifeel more restless or wound up than usual.

2 I am so restless or agitated that it's hard to stay still.

3 I am so restless or agitated that I have to keep moving or doing something.

12. Loss of interest

$0 \quad$ I have not lost interest in other people or activities.

$1 \quad$ I am less interested in other people or things than before.

$2 \quad$ I have lost most of my interest in other people or things.

$3 \quad$ It's hard to get interested in anything.

13. Indecisiveness

O I make decisions about as well as ever.

$1 \quad$ Ifind it more difficult to make decisions than usual.

$2 \quad$ I have much greater difficulty in making decisions than I used to.

$3 \quad$ I have trouble making any decisions.

14. Worthlessness

o I do not feel I am worthless.

1 I don't consider myself as worthwhile and useful as I used to.

2 Ifeel more worthless as compared to other people. 
$3 \quad$ Ifeel utterly worthless.

15. Loss of energy

$0 \quad$ I have as much energy as ever.

$1 \quad$ I have less energy than I used to have.

2 I don't have enough energy to do very much.

3 I don't have enough energy to do anything.

16. Changes in sleeping pattern

$0 \quad$ I have not experienced any change in my sleeping pattern.

la I sleep somewhat more than usual.

$1 b \quad$ I sleep somewhat less than usual.

$2 a \quad$ I sleep a lot more than usual.

$2 b \quad$ I sleep a lot less than usual.

$3 a \quad$ I sleep most of the day.

$3 b \quad$ I wake up 1-2 hours early and can't get back to sleep.

17. Irritability

o I am no more irritable than usual.

$1 \quad$ I am more irritable than usual.

2 I am much more irritable than usual.

3 I am irritable all the time.

18. Changes in appetite

$0 \quad$ I have not experienced any change in my appetite.

1a My appetite is somewhat less than usual.

$1 b \quad$ My appetite is somewhat greater than usual.

$2 a \quad$ My appetite is much less than before.

$2 b \quad$ My appetite is much greater than usual.

$3 a \quad$ I have no appetite at all.

$3 b \quad$ I crave food all the time.

19. Concentration difficulty

o I can concentrate as well as ever.

$1 \quad$ I can't concentrate as well as usual.

2 It's hard to keep my mind on anything for very long.

$3 \quad$ I find I can't concentrate on anything.

20. Tiredness or fatigue

o I am no more tired or fatigued than usual.

1 I get more tired or fatigued more easily than usual.

2 I am too tired or fatigued to do a lot of the things I used to do.

3 I am too tired or fatigued to do most of the things I used to do.

21. Loss of interest in sex

$0 \quad$ I have not noticed any recent change in my interest in sex.

$1 \quad$ I am less interested in sex than I used to be. 
2 I am much less interested in sex than I used to be.

$3 \quad$ I have lost interest in sex completely. 
Appendix F

Semi-structured Interview Guide

Introductory Script: The interview portion of this study will ask you open-ended questions about your experience of violence or abuse with another woman partner in the past. We will begin more generally, then I will ask you to consider more specific ways that you and your partner used power to influence or control one another. From time to time, I may ask a follow up question before asking you the next interview question, in order to clarify or elaborate on an idea you express. I will check in with you throughout the interview, but if you decide you need a break or to stop the interview please let me know. Do you have any questions before we begin?

1. Can you tell me about your past relationship? (Elicit information related to partner's gender identity and sexual orientation) (Elicit specific ways as needed $\downarrow$ )

a) At any point did either you or your partner experience any violence?

b) What kind of acts occurred during the relationship?

way?

i) Physical acts where either of you were touched or struck in some

etc...)

degrading?

ii) Threats of physical or verbal harm? Intimidation? (to self, other, pet,

iii) Verbal or emotional acts where either of you were critical, mean, or

iv) Sexual acts or threats that occurred without consent?

2. Describe ways that you feel you had control over your partner? (Elicit specific ways as needed $\downarrow$ )

a) How did you handle everyday decisions?

b) How did you handle disagreements or concerns you had with your partner?

c) How did you react if your partner wanted to do things independently or pursued outside interests?

d) How did you handle finances and decisions about money?

e) How did you handle sexual decisions?

f) In what ways, if any, did you question your partner's sexuality (outing)? Other identities?

g) What were your expectations about the friendships/relationships your partner had?

h) Did you ever threaten or try to kill or harm yourself as a means to control your partner?

i) Did you ever use drugs or alcohol in effort to control your partner? Did they factor into any abusive incidents?

3. Describe ways that you feel your partner had control over you? (Elicit specific ways as needed $\downarrow$ )

a) How did they handle everyday decisions?

b) How did they handle disagreements or concerns they had with you? 
c) How did your partner react if you wanted to do things independently or pursued outside interests?

d) How did they handle finances and decisions about money?

e) How did they handle sexual decisions?

f) In what ways, if any, did they question your sexuality (outing)? Other identities? had?

g) What were their expectations about the friendships/relationships you partner

h) Did your partner ever threaten or try to kill or harm herself as a means to control you?

i) Did your partner ever use drugs or alcohol in effort to control you? Did they factor into any abusive incidents?

4. Sometimes we have power and influence that we do not always easily recognized. Were there ways you or your partner had control in the relationship that may not be traditionally expected? (Elicit specific ways as needed $\downarrow$ )

a) Did you or your partner portray the abuse as mutual or consensual at times, when maybe it was not? ones?

b) Did you or your partner isolate one another from social networks or loved

c) Did you or your partner use your social privilege to hurt one another or put one another in danger? Privilege includes any advantages a person has based on their position in society or the value placed on certain identities that they possess.

5. Describe the pattern of violence or abuse in your relationship? (Elicit specific ways as needed $\downarrow$ )

a) Did the abuse increase or decrease over time?

b) Was the cycle of abuse predictable, with periods of calm followed by chaos?

c) Did you see the abusive acts as one sided or mutual throughout the relationship?

6. When the relationship ended, did your behavior toward your new partner change as a result of being with an abusive partner?

7. Getting help when you are involved in an abusive or difficult relationship can seem impossible at times. What would you have needed to seek help from loved ones, shelters, counselors, or other professionals?

a) What barriers did you experience in trying to seek help?

b) Who or what enabled you to end the abuse?

8. Also, if you had the opportunity to speak to clinicians, teachers, and parents regarding same sex partner violence, what would you like them to know?

Follow up question, post interview: 
Imagine you had a friend who had a similar experience and was considering participating in the study. What would you say about your experience? Would you recommend they participate? 


\section{Appendix G \\ Domestic Violence Resources}

If at any time during the screening process, phone interview, or post interview, you find yourself distressed at the prompts or topics discussed the following organizations provide support for individuals who identify as LGBTQ. Both phone and web resources are available.

If you are in immediate danger, please call 911.

The National Domestic Violence Hotline 1-800-799-7233

www.thehotline.org (online chat available)

The National Coalition of Anti-Violence Programs (NCAVP) Hotline 212-714-1141

Lifewire - Together Against Domestic Violence Hotline $1-800-827-8840$

National Suicide Prevention Lifeline

1-800-273-TALK (8255)

Www.suicidepreventionlifeline.org (online chat available)

GLBTQ Domestic Violence Project Hotline

$1-800-832-1901$

The Network/La Red Hotline (Violence against LGBTQ, SM/Kink, \& Polyamourous communities)

617-742-4911 (Spanish support available)

Violence Recovery Program at Fenway Community Health

1-800-834-3242

GLBT National Hotline

$1-888-843-4564$ 


\section{BIBLIOGRAPHY}

Alhusen, J. L., Lucea, M. B., \& Glass, N. (2010). Perceptions of and experience with system responses to female same-sex intimate partner violence. Partner Abuse, 1(4), 443-462. doi:10.1891/1946-6560.1.4.443

Aselton, P. (2012). Using the internet for qualitative research in Nursing. Journal of Nursing \& Care, 1(1), 126-128.

Baker, N. L., Buick, J. D., Kim, S. R., Moniz, S., \& Nava, K. L. (2013). Lessons from examining same-sex intimate partner violence. Sex Roles, 69(3-4), 182-192.

Balsam, K. F. (2002). Traumatic victimization in the lives of lesbian and bisexual women: A contextual approach. Journal of Lesbian Studies, 7(1), 1-14.

Balsam, K. F., Rothblum, E. D., \& Beauchaine, T. P. (2005). Victimization over the life span: A comparison of lesbian, gay, bisexual, and heterosexual siblings. Journal of Consulting and Clinical Psychology, 73, 477-487.

Balsam, K. F., \& Szymanski, D. M. (2005). Relationship quality and domestic violence in women's same-sex relationships: the role of minority stress. Psychology of Women Quarterly, 29(3), 258-269.

Basow, S. A., \& Thompson, J. (2012). Service providers' reactions to intimate partner violence as a function of victim sexual orientation and type of abuse. Journal Of Interpersonal Violence, 27(7), 1225-1241. doi:10.1177/0886260511425241

Beck, C. T. (1993). Qualitative research: the evaluation of its credibility, fittingness, and auditability. Western Journal of Nursing Research, (15), 263-6. 
Beck, C. T. (1993). Teetering on the edge: A substantive theory of postpartum depression. Nursing research, 42(1), 42-48.

Beck, A. T., Steer, R. A., \& Brown, G. K. (1996). Manual for the Beck Depression Inventory-II. San Antonio, TX: Psychology Corporation.

Black, M.C., Basile, K.C., Breiding, M.J., Smith, S.G., Walters, M.L., Merrick, M.T., Chen, J., \& Stevens, M.R. (2011). The National Intimate Partner and Sexual Violence Survey (NISVS): 2010 Summary Report. Atlanta, GA: National Center for Injury Prevention and Control, Centers for Disease Control and Prevention.

Blasko, K. A., Winek, J., \& Bieschke, K. J. (2007). Prototypical assessment by therapists of domestic violence situations. Journal of Marital and Family Therapy, 33, 258269.

Bornstein, D. R., Fawcett, J., Sullivan, M., Senturia, K. D., \& Shiu-Thornton, S. (2006). Understanding the experiences of lesbian, bisexual and trans survivors of domestic violence: A qualitative study. Journal of Homosexuality, 51(1), $159-181$.

Brown, C. (2008). Gender-role implications on same-sex intimate partner abuse. Journal of Family Violence, 23(6), 457-462.

Cahn, D. D. (1996). Family Violence from a Communication Perspective. In D.D. Cahn \& S. A. Lloyd (Eds.), Family violence from a communication perspective (pp. 1-19). Thousand Oaks, CA: Sage. 
Dank, M., Lachman, P., Zweig, J. M., \& Yahner, J. (2014). Dating violence experiences of lesbian, gay, bisexual, and transgender youth. Journal of Youth and Adolescence, 43(5), 846-857.

Eaton, L., Kaufman, M., Fuhrel, A., Cain, D., Cherry, C., Pope, H., \& Kalichman, S. C. (2008). Examining factors co-existing with interpersonal violence in lesbian relationships. Journal Of Family Violence, 23(8), 697-705. doi:10.1007/s10896-008-9194-3

Follingstad, D. R., \& Ryan, K. M. (2013). Contemporary issues in the measurement of partner violence. Sex Roles, 69(3-4), 115-119.

Ford, C. L., Slavin, T., Hilton, K. L., \& Holt, S. L. (2012). Intimate partner violence prevention services and resources in Los Angeles: Issues, needs, and challenges for assisting lesbian, gay, bisexual, and transgender Clients. Health Promotion Practice, 14(6), 841-849. doi:10.1177/1524839912467645

Goldberg, N. G., \& Meyer, I. H. (2013). Sexual orientation disparities in history of intimate partner violence: Results from the California health interview survey. Journal Of Interpersonal Violence, 28(5), 1109-1118. doi: $10.1177 / 0886260512459384$

Graneheim, U. H., \& Lundman, B. (2004). Qualitative content analysis in nursing research: concepts, procedures and measures to achieve trustworthiness. Nurse Education Today, 24(2), 105-112.

Hamberger, L., \& Phelan, M. (2006). Domestic violence screening in medical and mental health care settings: Overcoming barriers to screening, identifying, and 
helping partner violence victims. Journal Of Aggression, Maltreatment \& Trauma, 13(3-4), 61-99. doi:10.1300/J146v13n03_04

Hardesty, J. L., Oswald, R. F., Khaw, L., \& Fonseca, C. (2011). Lesbian/bisexual mothers and intimate partner violence: Help seeking in the context of social and legal vulnerability. Violence Against Women, 17(1), 28-46.

doi:10.1177/1077801209347636

Hart, B. (1986). Lesbian battering: An examination. In K. Lobel (Ed.), Naming the violence: Speaking out about lesbian battering (pp. 173-189). Seattle, WA: The Seal Press.

Hassouneh, D., \& Glass, N. (2008). The influence of gender role stereotyping on women's experiences of female same-sex intimate partner violence. Violence Against Women, 14(3), 310-325. doi:10.1177/1077801207313734

Helfrich, C. A., \& Simpson, E. K. (2006). Improving Services for Lesbian Clients: What Do Domestic Violence Agencies Need to Do? Health Care For Women International, 27(4), 344-361. doi:10.1080/07399330500511725

Hill, N. A., Woodson, K. M., Ferguson, A. D., \& Parks, C. R. (2012). Intimate partner abuse among African American lesbians: Prevalence, risk factors, theory, and resilience. Journal Of Family Violence, 27(5), 401-413. doi:10.1007/s10896012-9439-Z

James, N. (2007). The use of email interviewing as a qualitative method of inquiry in educational research. British Educational Research Journal, 33(6), 963-976.

Jenkins, S. R. (2000). Introduction to the special issue: defining gender, relationships, and power. Sex Roles, 42(7/8), 467-493. 
Landolt, M.A., \& Dutton, D.G. (1997). Power and personality: An analysis of gay male intimate abuse. Sex Roles, 37, 335-359.

Lincoln, Y.S., \& Guba, E.G. (1985). Naturalistic inquiry. Newbury Park, CA: Sage.

Mason, T. B., Lewis, R. J., Milletich, R. J., Kelley, M. L., Minifie, J. B., \& Derlega, V. J. (2014). Psychological aggression in lesbian, gay, and bisexual individuals' intimate relationships: A review of prevalence, correlates, and measurement issues. Aggression and Violent Behavior, 19(3), 219-234.

Matte, M., \& Lafontaine, M. (2011). Validation of a measure of psychological aggression in same-sex couples: Descriptive data on perpetration and victimization and their association with physical violence. Journal of GLBT Family Studies, 7, 226-244.

McClennen, J. C. (2005). Domestic violence between same-gender partners: Recent findings and future research. Journal of Interpersonal Violence, 20(2), 149154. doi: $10.1177 / 0886260504268762$

McClennen, J. C., Summers, A. B., \& Daley, J. G. (2002). The lesbian partner abuse scale. Research on Social Work Practice, 12(2), 277-292.

Mendez, J. M. (1996). Serving gays and lesbians of color who are survivors of domestic violence. Journal of Gay \& Lesbian Social Services, 4(1), 53-60.

Meyer, I. H., \& Wilson, P. A. (2009). Sampling lesbian, gay, and bisexual populations. Journal of Counseling Psychology, 56, 23-31.

Merlis, S. R., \& Linville, D. (2006). Exploring a community's response to lesbian domestic violence through the voices of providers: A qualitative study. Journal 
of Feminist Family Therapy: An International Forum, 18(1-2), 97-136. doi:10.1300/J086v18n01_05

National Coalition of Anti-Violence Programs (NCAVP). (2014). 2013 Report on Lesbian, Gay, Bisexual, Transgender and HIV-Affected Intimate Partner Violence. New York, NY.

Orsillo, S. M. (2001). Measures for acute stress disorder and posttraumatic stress disorder. In M. M. Antony \& S. M. Orsillo (Eds.), Practitioner's guide to empirically based measures of anxiety (pp. 255-307). New York: Springer US.

Oswald, R. F., Fonseca, C. A., \& Hardesty, J. L. (2010). Lesbian mothers' counseling experiences in the context of intimate partner violence. Psychology of Women Quarterly, 34(3), 286-296. doi:10.1111/j.1471-6402.2010.01575.x

Polit, D. F., \& Beck, C. T. (2008). Nursing research: Generating and assessing evidence for nursing practice. Lippincott Williams \& Wilkins.

Poorman, P. B. (2001). Forging community links to address abuse in lesbian relationships. Women \& Therapy, 23(3), 7-24. doi:10.1300/J015v23n03_02

Renzetti, C. M. (1992). Violent betrayal: Partner abuse in lesbian relationships. Sage Publications.

Ristock, J. L. (2001). Decentering heterosexuality: Responses of feminist counselors to abuse in lesbian relationships. Women \& Therapy, 23(3), 59-72.

Ristock, J. L. (2003). Exploring dynamics of abusive lesbian relationships: Preliminary analysis of a multisite, qualitative study. American Journal of Community Psychology, 31(3-4), 329-341. doi:10.1023/A:1023971006882 
Seedat, S., Stein, M. B., \& Forde, D. R. (2005). Association between physical partner violence, posttraumatic stress, childhood trauma, and suicide attempts in a community sample of women. Violence and Victims, 20(1), 87-98. doi:10.1891/vivi.2005.20.1.87

Seelau, S. M., \& Seelau, E. P. (2005). Gender-role stereotypes and perceptions of heterosexual, gay and lesbian domestic violence. Journal of Family Violence, 20(6), 363-371.

Singh, V., Petersen, K., \& Singh, S. R. (2014). Intimate partner violence victimization: identification and response in primary care. Primary Care, 41(2), 261-281. doi:10.1016/j.pop.2014.02.005

Singh, A., \& Shelton, K. (2011). A content analysis of lgbtq qualitative research in counseling: A ten-year review. Journal of Counseling \& Development, 89(2), 217-226.

Stevens, S., Korchmaros, J. D., \& Miller, D. (2010). A comparison of victimization and perpetration of intimate partner violence among drug abusing heterosexual and lesbian women. Journal of Family Violence, 25(7), 639-649. doi:10.1007/s10896-010-9321-9

Sturges, J. E., \& Hanrahan, K. J. (2004). Comparing telephone and face-to-face qualitative interviewing: A research note. Qualitative Research, 4(1), 107-118.

Waalen, J., Goodwin, M. M., Spitz, A. M., Petersen, R., \& Saltzman, L. E. (2000). Screening for intimate partner violence by health care providers: barriers and interventions. American Journal of Preventive Medicine, 19(4), 230-237. 
Weathers, F., Litz, B., Herman, D., Huska, J., \& Keane, T. (October 1993). The PTSD Checklist (PCL): Reliability, Validity, and Diagnostic Utility. Paper presented at the Annual Convention of the International Society for Traumatic Stress Studies, San Antonio, TX.

West, C. M. (2002). Lesbian intimate partner violence: Prevalence and dynamics. Journal of Lesbian Studies, 6(1), 121-127. doi:10.1300/J155v06n01_11

West, C. M. (2012). Partner abuse in ethnic minority and gay, lesbian, bisexual, and transgender populations. Partner Abuse, 3(3), 336-357. doi:10.1891/19466560.3 .3 .336

Zipkin, D. (1999). The myth of the short-haired lesbian. Journal of lesbian studies, 3(4), 91-101. 